\title{
La desigualdad de ingresos en el Perú según el censo de 1876
}

\author{
Paula Castillo Vera*
}

\begin{abstract}
RESUMEN
La desigualdad es un fenómeno social que existe en todas las naciones, es una condición que implica que las personas no gocen del mismo acceso a los recursos de todo tipo y a ciertas posiciones que valora la sociedad. A pesar de la importancia, en el Perú, estimaciones sobre diferentes enfoques de la desigualdad fueron abordados a partir del siglo XX debido a que desde aquella época recién se elaboran datos que hicieron posible su estudio.

Dado que no existen estimaciones detalladas sobre la desigualdad antes del siglo XX, el objetivo de este estudio es estimar la desigualdad de ingresos en el Perú a finales del siglo XIX tomando como base al censo de 1876, primer censo de población y vivienda de la Época Republicana. Se le considera el más importante por ser el que contó con técnicas modernas para el empadronamiento de los habitantes de aquella época.
\end{abstract}

Palabras clave: Desigualdad de ingresos, Censo Nacional Peruano 1876

Código JEL: N36

Income Inequality in Peru According to 1876 Census

\begin{abstract}
Inequality is a social phenomenon that exists across all nations; it is a condition which means that not everyone enjoys the same access to resources of all kinds and to certain positions that society values. Despite its importance, in Peru, the analysis of different approaches to inequality was not taken up until the 20th century, since it was only then that data began to be prepared to enable its study.

Because detailed analyses of inequality did not exist before the 20th century, the objective of this study is to estimate income inequality in Peru at the end of the 19th century on the basis of the 1876 census, the first population and housing census of the Republican era. This census is considered to be particularly important for its utilization of modern techniques to enumerate the inhabitants of the day.
\end{abstract}

Keywords: Historical Income Inequality, National Peruvian Census1876

JEL Codes: N36

* Licenciada en Economía y bachiller por la Pontificia Universidad Católica del Perú. El presente documento es una adaptación de la tesis de licenciatura. 


\section{LA MEDICIÓN DE LA DESIGUALDAD EN LA HISTORIA DEL PERÚ}

La sociedad colonial peruana se caracterizó por estar socialmente jerarquizada, donde los únicos que poseían la totalidad de los derechos y beneficios eran los colonos y autoridades políticas y religiosas. La etnicidad jugó un papel de exclusión social para la sociedad formada, pues la Corona española estableció una república de españoles y otra de indios que se relacionaron únicamente a través del control que ejerció el Estado representado por los corregidores. Así, los espańoles y sus descendientes contaron con privilegios para acceder a tierras ricas para la explotación de recursos naturales. Sin embargo, esta clase constituyó alrededor del $10 \%$ de la población mientras que el grupo de los indígenas oscilaba entre $56 \%$ a $60 \%$, a pesar de que en el proceso de colonización se eliminó a una proporción considerable de estos últimos ${ }^{1}$.

Además de ser propietarios de ricas extensiones de tierras y desempeñarse en cargos de autoridad, los espańoles también estaban presentes en la rama del comercio ultramarino. Por otro lado, los mestizos que fueron incrementándose y fortaleciéndose como grupo social también participaron en los mismos rubros que los españoles, pero con menores rangos pues ocuparon puestos como alcaldes de pueblos pequeños, cobradores de impuestos y correos mayores. Mientras que los indígenas vivían bajo una economía de autosubsistencia, obligados a pagar tributos y a emplearse en trabajos como peones mineros. No obstante, el descontento de la población surgió por la presencia de una fuerte desigualdad y se produjeron rebeliones a partir de 1726, que culminaron con la rebelión de $1780-1781^{2}$ encabezada por la élite indígena, mestizos y criollos. Esto solo originó mayor represión por la élite española hasta la llegada de la independencia.

La desigualdad formada en la colonia transcendió hasta la época de la independencia y pese a las constantes rebeliones, no pudo ser completamente eliminada. A esto se le sumó la desigualdad entre la costa y la sierra, pues antes de la independencia, la sierra fue el eje económico del país, ya que las élites pertenecientes a dicha región habían controlado la mano de obra indígena utilizada, en su mayoría, para la actividad minera; sin embargo, la configuración realizada por la independencia, reforzada por el boom guanero, cambió el eje de dominación absoluto hacia Lima.

Uno de los más importantes estudios sobre la desigualdad en el Perú del siglo XX, fue publicado por Richard Webb y Adolfo Figueroa bajo el título «Distribución del ingreso para el Perú». Webb trabaja con datos para 1961 y divide en deciles ${ }^{3}$ a la fuerza

\footnotetext{
1 Se estimó que la población indígena antes de la conquista llegó a ser 2738673 personas, la cual se redujo a 601645 para 1630 (Thorp, Paredes y Contreras, 2011, p. 119).

2 La rebelión fue liderada por José Gabriel Condorcanqui, mejor conocido como Túpac Amaru II, en reacción a la imposición de las Reformas Borbónicas. Esta rebelión articuló a sectores sociales muy diversos, como a criollos e indígenas e incluso parte del clero, pues tenían un gran descontento debido a los tributos excesivos, la mita y abusos de corregidores entre otros.

3 Los primeros deciles representan a la población más rica y los deciles inferiores, a los más pobres.
} 
laboral según niveles de ingreso. De acuerdo a sus resultados, la estimación muestra un alto nivel de desigualdad, pues el primer decil de la fuerza laboral concentra aproximadamente un $49 \%$ del ingreso, mientras que los seis últimos deciles inferiores solo concentran el 18,2\%. Para el periodo 1950-1966, Webb concluye que los ingresos provenientes del trabajo se volvieron más desiguales. La población rural de la sierra y algunos otros grupos de artesanos e independientes, habrían empobrecido relativamente durante los años analizados. Mientras que las más altas tasas de crecimiento se produjeron en el sector moderno (empresas registradas, empleados públicos y profesionales).

Por otro lado, Figueroa dentro de su análisis hecho para ocho países latinoamericanos entre las décadas de 1950 y 1960, estima un índice de Gini de 0,62 para el Perú. Aquel índice fue el más alto de la muestra y señala que el $60 \%$ más pobre del país recibe apenas $17 \%$ del ingreso nacional en tanto que el $5 \%$ más rico recibe $40 \%$.

Para estimaciones del coeficiente de Gini de periodos más recientes, se tiene a Yamada y Castro (2006) quienes calculan el índice a partir de una corrección ${ }^{4}$ por cuentas nacionales, pues encuentran que el índice oficial estimado únicamente con la Encuesta Nacional de Hogares (ENAHO), subestima el nivel de desigualdad. Por ejemplo, para el año 2004 calcularon un Gini de 0,48 según la ENAHO, mientras que a partir de las cuentas nacionales obtuvieron un Gini de 0,69.

Asimismo, Escobal y Ponce (2006) hallan un Gini ${ }^{5}$ que gira en torno a 0,5 para los ańos 1985, 1994, 2004, 2006 y 2009. Mientras que Mendoza, Leiva y Flor (2010) estiman que para el periodo 1980-2010 el valor del Gini ${ }^{6}$ fue de 0,6.

En suma, las estimaciones de la desigualdad realizadas por cada autor, coinciden en que dicho nivel se ha mantenido alto por largos períodos de tiempo a pesar del constante crecimiento del PBI per cápita. Además, el factor étnico jugó un papel muy importante en la determinación de la desigualdad, en especial, en el siglo XX. Otro factor que también determinó el nivel de desigualdad es la geografía, pues los territorios pertenecientes a la sierra del país albergaron a una población agrícola con ingresos muy bajos.

\footnotetext{
4 La ENAHO captura casi toda la información de consumo de los grupos inferiores, mientras que no es fuente confiable para analizar el consumo de las clases más ricas, puesto que estas normalmente tienden a no declarar. Por lo que los autores reemplazan la media del consumo de la encuesta de hogares con su similar de las cuentas nacionales y así se ajustan los coeficientes de Gini.

5 Utilizan la corrección por cuentas nacionales a través de la metodología de Elbers, Lanjouw y Lanjouw (2004) donde se demuestra que el Gini corregido es mayor que el oficial.

6 Realizan una corrección del Gini con la serie del PBI per cápita y con la serie del PNB per cápita.
} 


\section{EL CENSO DE 1876: INTENTOS PREVIOS}

Paul Gootenberg (1995) señala que entre 1790 y 1876 tomaron lugar los primeros censos nacionales, sin embargo, estos se elaboraron sobre la base de las matrículas del tributo de indios y castas, conocidos como registros fiscales, mas no en una encuesta que cubriera todo el territorio nacional. El primero de ellos se llevó a cabo en 1791 bajo el mandato del virrey Gil de Taboada y Lemus, sin embargo, no fue posible completar el censo en su totalidad debido a la poca preparación de los funcionarios, sin embargo, entre los datos que se lograron recolectar se encuentran la cantidad de habitantes y su distribución por provincia, así como la clasificación por raza y religión. Posteriormente, se realizó un intento de elaboración de un censo en 1836, pero dado que se basó en registros fiscales, no fue considerado un censo oficial. Sin embargo, hacia 1848, con la creación del Consejo Central Directivo de Estadística General, se empiezan a elaborar estadísticas más confiables.

Hacia 1850 se construyó un censo que obtuvo cifras más exactas de la población en el país, no obstante, el de 1876 fue considerado el mejor censo elaborado en el siglo XIX. Este se elaboró bajo el gobierno de Manuel Pardo (1872-1876), quien contrató al estadístico francés George Marchand para que lo dirigiera. Los resultados fueron compilados y publicados por Manuel Atanasio Fuentes quien ejerció el cargo de Director de Estadística durante el gobierno de Pardo. La metodología que se utilizó para su elaboración consistió en la entrega de formularios en blanco a la población para transferirle la responsabilidad de llenarlos y remitirlos a las autoridades. En las zonas donde no era posible aplicar el censo de esta manera, se organizó un grupo de empadronadores (Cosamalón, 2012). De esta forma se elabora el censo de 1876, el primer censo con cifras oficiales que incluyó datos laborales, sociales y regionales en la historia de la República del Perú.

Uno de los análisis más importantes sobre la distribución de ingresos en el siglo XIX, fue el realizado por Shane Hunt ${ }^{7}$, ya que proporcionó la distribución ocupacional de la fuerza de trabajo y la dividió en categorías salariales. Para la división de las ocupaciones creó once grandes categorías ${ }^{8}$ en las cuales incluye a agricultores masculinos y femeninos, sin embargo, en el caso de otras ocupaciones solo consideró a la fuerza de trabajo masculina.

Para la distribución salarial, Hunt utilizó las cifras de salario propuestas por Jean Baptiste Martinet, doctor francés en ciencias agrícolas. Según este, el jornal promedio aproximado para Lima de 1876-77 fue de 0,80 soles. Tomando como base esta cifra,

\footnotetext{
7 Doctor y máster en Economía de la Universidad de Yale. Entre sus publicaciones se encuentran Latin American Economies: Growth and the Export Sector, 1880-1930; El problema del empleo en el Perú, entre otros. 8 Agricultura y ganadería, pesca, minería, industria, construcción, transporte, comunicaciones, comercio, servicios, empleados no asignados y, sin clasificar.
} 
distribuye a la población sobre la base de las categorías salariales ${ }^{9}$ de 1866 publicadas por José Manuel Rodríguez ${ }^{10}$ (1895) y obtiene así, el ingreso nacional del Perú de 1876-1877.

De acuerdo a los resultados de Hunt, el 60,4\% de la fuerza de trabajo estuvo compuesta por agricultores, seguidos por las hilanderas y las ocupaciones femeninas de remuneración baja con $12,8 \%$ y $12,7 \%$, respectivamente. En relación al ingreso per cápita, las hilanderas eran la fuerza de trabajo con el menor ingreso, seguido de las ocupaciones femeninas de remuneración baja y los agricultores y jornaleros. Aproximadamente un $60 \%$ de la fuerza laboral se dedicaba a la agricultura la cual tiene retornos muy bajos, por lo que se podría decir que la población del Perú de 1876-77 era mayoritariamente pobre.

Por otro lado Albert Berry ${ }^{11}$, autor de varias publicaciones ${ }^{12}$ entre las que se encuentra el análisis sobre la distribución de ingresos y desigualdad para el Perú de finales del siglo XIX, presenta, bajo el título de "International trade, government, and income distribution in Peru since 1870", una alternativa para la medición de la desigualdad sobre la base del censo de 1876. Según su hipótesis, el boom de las exportaciones tradicionales empeoró la distribución de ingresos. Berry inicia su análisis a partir de la estimación que realiza Hunt para el periodo 1876-1877.

$\mathrm{Al}$ igual que en la estimación de Hunt, la categoría con menores ingresos per cápita anual, lo conforman las hilanderas (S/. 59), seguida de las ocupaciones con bajo salario para las mujeres (S/. 97). Sin embargo, Berry afirma que solo se tiene una limitada credibilidad a las cifras de 1876, pero al no haber otra data con resultados más precisos, el análisis sugiere que la desigualdad en su totalidad no es muy diferente ahora de lo que fue en aquella época.

El tipo de análisis elaborado por cada autor es diferente, sin embargo, ambos resultados buscan caracterizar el nivel de desigualdad en la distribución de ingresos para el Perú del siglo XIX. Shane Hunt, utiliza fuentes de autores reconocidos que retrataron de la forma más fiel el contexto socio económico del Perú de aquella época, como Jean B. Martinet, Manuel A. Fuentes y J. M. Rodríguez. No obstante, en su estimación no se consideraron todas las ocupaciones que menciona el censo de 1876, fuente básica

\footnotetext{
9 El régimen dictatorial de Mariano Ignacio Prado (1865-1867), tuvo como parte importante de su plan, la reincorporación de la población indígena al sistema fiscal. Su ministro de Hacienda, Manuel Pardo, justificó la medida por un principio de equidad tributaria, pues la extensión de las contribuciones a toda la población era algo fundamental. Es por esto que las categorías salariales se establecieron en 1866 para implementar la contribución personal; estas se dividieron en seis y agruparon a las provincias de acuerdo con el nivel del jornal prevaleciente.

${ }_{10}$ Director y fundador de la revista Economista Peruano.

${ }^{11}$ Profesor emérito de economía de la Universidad de Toronto que trabajó para la Fundación Ford, el Banco Mundial, entre otros.

12 Critical Issues in International Financial Reform (2003), publicación que comparte con Gustavo Indart; Labor Market Policies in Canada and Latin America. Challenges of the New Millennium (2001); Poverty, Economic Reform, and Income Distribution in Latin America; entre otras.
} 
de su estudio, ni tampoco considera a la totalidad de las provincias del país para la asignación del salario, por lo que sus cifras pueden ser consideradas como referencias generales, mas no precisas ${ }^{13}$. De igual manera, las estimaciones realizadas por Albert Berry dejan aún preguntas por responder en cuanto a su metodología, sin embargo, elabora un juicio crítico del contexto económico que experimentó el Perú en el siglo XIX a partir del boom de las exportaciones tradicionales.

Finalmente, cabe mencionar que las estimaciones realizadas por cada autor son las únicas que se han presentado sobre distribución de ingresos a finales del siglo XIX en el Perú y son valiosas, en tanto brindan un panorama detallado del contexto económico de la época ${ }^{14}$.

\section{CONTEXTO ECONÓMICO Y SOCIAL DEL PERÚ DE 1876}

\subsection{SituaCión FisCAL}

Hacia 1870, el modelo fiscal vigente en el Perú estuvo basado en los ingresos por la exportación del guano. Al inicio de aquella década se empezaron a sentir los efectos de la crisis fiscal producida, entre otros factores, por el excesivo gasto público. El punto de quiebre se habría originado en el régimen de José Balta (1868-1872); su programa se basó en la construcción de obras públicas, principalmente de ferrocarriles, pero dado que se encontró con un tesoro fiscal venido a menos, buscó alternativas para mejorar la situación a través de la contratación de un empréstito externo financiado por la consignación del guano. Los empréstitos de 1870 y 1872 pactados con la Casa Dreyfus, comprometieron seriamente los ingresos futuros del país y a pesar de ser cuantiosas sumas de dinero, no se pudo solventar el plan de ferrocarriles de Balta, lo que obligó al Estado a recurrir al crédito externo.

El país estuvo inmerso en un profundo endeudamiento, por lo que entre los ańos 1873 y 1876 aproximadamente, la mitad del presupuesto fue destinado a cubrir la deuda externa contraída entre 1865 y 1872, lo que causó que lo destinado para cubrir el gasto interno fuera disminuyendo en 1873 (Contreras, 2012, p. 101). Los ingresos por guano eran inexistentes en este punto pues la venta del fertilizante estaba afecta al pago del servicio de la deuda externa y al reembolso de los adelantos a Dreyfus. En el gobierno de Pardo (1872-1876) se produjeron intentos por aumentar la recaudación a través de la descentralización fiscal, de la expropiación del salitre, del aumento de los derechos

\footnotetext{
13 En el inicio del Apéndice del capítulo 2 de su libro La formación de la economía peruana, el mismo autor reconoce el carácter rudimentario de su estimación.

${ }^{14}$ Linda Twrdek y Kerstin Manzel (2013) publicaron un estudio en el que analizan el nivel de vida de la población peruana del siglo XIX a través del desarrollo de las estaturas. Este estudio se titula, "La semilla de la abundancia y la miseria. Niveles de vida peruanos desde los inicios del periodo republicano hasta el fin de la era del guano (1820-1880)".
} 
aduaneros y mediante la negociación de un nuevo acuerdo con Dreyfus; no obstante, no se lograron los resultados esperados. Finalmente, para enfrentar la situación, el Gobierno optó por dos mecanismos, el primero consistió en recurrir a la banca privada nacional para solicitar un préstamo de 18 millones de soles destinados al financiamiento del déficit y otras obligaciones pendientes, mientras que por el segundo mecanismo se buscó a un reemplazo para Dreyfus, a través del contrato celebrado con la Societé Genérale de Paris en octubre de 1875, sin embargo, dicho contrato quedó sin efecto al no aceptar, la empresa, un adelanto solicitado por el Gobierno peruano.

Cuando Prado asume el gobierno, en agosto de 1876, el país se encontraba con un gran nivel de deuda externa e interna y un déficit aproximado para 1875-1876 de 47 millones de soles, a lo cual se agregaba una disminución notable en el consumo del guano. Sin embargo, en el contexto de crisis se desarrolló cierta diversificación productiva en otros sectores de la economía, como es el caso de la producción de azúcar y algodón. No obstante, el producto que logró mayor desarrollo fue el salitre. En el caso de la minería, su producción se mantuvo estacionaria, sin embargo, de acuerdo con los Anales de la Hacienda Pública del Perú ${ }^{15}$, con la creación de la contribución de minas en enero de 1877 se constituye el punto inicial para el resurgimiento de esta industria. A esto último habría que agregar que el fortalecimiento del sector también se debió a otros factores como la apertura de la Escuela de Ingenieros (1876), obras ferroviarias y la mejora en los derechos de propiedad, con esto último se generó mayor confianza para la inversión en el sector minero.

En suma, el contexto económico nacional hacia 1876, estuvo caracterizado por una época de crisis fiscal cuya esperanza radicaba en los ingresos por guano, pero al encontrarse estos consumidos por la deuda externa, se buscó un reemplazo en el salitre, originando la expropiación de las salitreras que produjo una grieta en la relación entre el empresariado y el Estado. Por otro lado, algunas industrias nacionales se desarrollaban paralelamente, aunque claro, sus ingresos significaron una pequeña proporción del ingreso nacional.

\subsection{La POBLACIÓN SEGÚN EL CENSO DE 1876}

El censo de 1876 contabilizó a 2699106 habitantes en la República del Perú, de los cuales, el 50,4\% eran hombres y 49,6\% mujeres. Existieron dieciocho departamentos, dos provincias litorales (Moquegua y Tarapacá) y una provincia constitucional (Callao). Los departamentos que concentraron la mayor cantidad de habitantes fueron Áncash, Puno, Cuzco, Lima, Cajamarca y Junín pues entre ellos se concentraba el 53\% de la población total del país.

15 Tomo X. 
Gráfico 1. Distribución de la población por departamentos, 1876 (En \%)

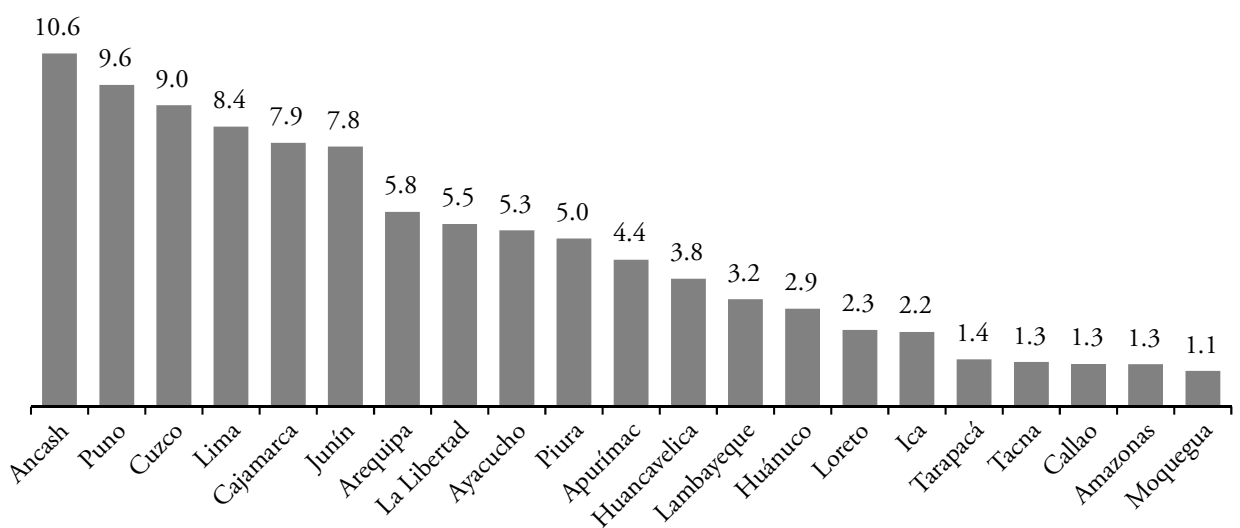

Fuente: Elaboración propia sobre la base del Censo de 1876. Ver anexo 1.

En cuestión de las razas identificadas en el censo, existieron cinco grandes categorías: blancos, indios, negros, mestizos y asiáticos. De estos, la raza indígena compuso el 57,6\% a nivel nacional, seguido de los mestizos con $24,8 \%$ y los blancos con $13,8 \%$, el resto estaba dividido entre los negros y asiáticos. Los departamentos cuya población era mayoritariamente indígena, fueron Puno (92\%), Huancavelica (79\%), Cuzco (75\%) y Ayacucho (72\%); por otro lado, Amazonas concentró una población de raza negra, mucho mayor al resto de los demás departamentos. Los asiáticos se establecieron en Lima, mientras que la raza blanca compuso gran parte de la población de Tarapacá y el Callao. Cabe mencionar además que casi la totalidad de la población era católica $(97,96 \%)$, mientras que el resto se dividía entre los cultos reformados, israelitas, otro cultos y cultos ignorados.

Gráfico 2. Distribución de razas por departamento, 1876

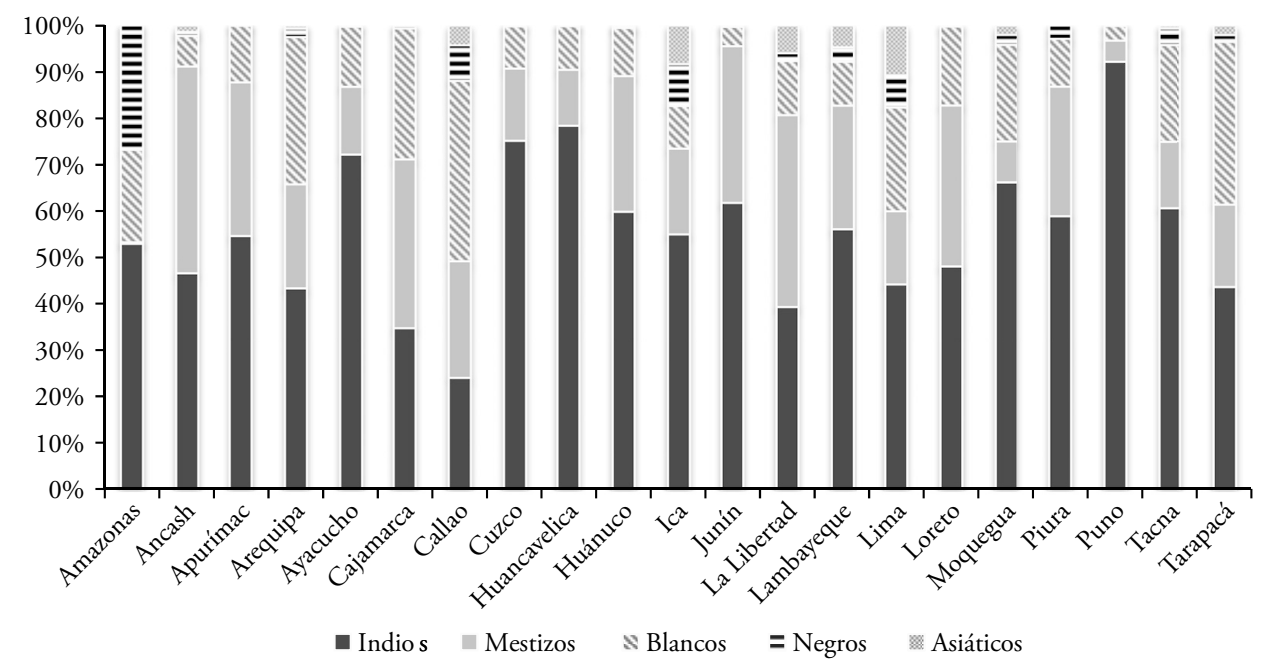

Fuente: Elaboración propia sobre la base del Censo de 1876. Ver anexo 3. 
La población de nacionalidad extranjera ascendió a 106962 personas (ver anexo $\mathrm{n}^{\circ} 3$ ), representando el 3,96\% del total de habitantes censados en el Perú. El 46,7\% de ellos eran asiáticos, seguidos de chilenos y bolivianos que llegaron a representar el 13,3\% y $11,5 \%$ respectivamente. El fenómeno migratorio estuvo dominado por la llegada de inmigrantes chinos a partir de la década de 1850 , contexto en el que se suprimió el tributo indígena y al mismo tiempo se abolió la esclavitud de los negros ${ }^{16}$. La consecuencia inmediata se produjo en la disminución de trabajadores en el campo, lo cual ponía en peligro a la agricultura; es por esto que se trae mano de obra china ${ }^{17}$ para ser comercializada dentro del país. Desde 1860 a 1874 la corriente de inmigración fue mucho más importante y el número de chinos embarcados al Perú llegó a 82 629, aunque de estos, el $11 \%$ falleció en el camino (Martinet, 1977, p. 51). No obstante, se produjo una suspensión de comercialización de culíes en $1874^{18}$, problema que fue superado después gracias a una misión diplomática en el mismo año a través de la celebración de un tratado entre Perú y China firmado en Tientsin ${ }^{19}$. Por otro lado, el gobierno peruano se ocupó también de atraer la emigración europea pues se pensaba que aquella población traería un gran contingente de civilización.

En lo que se refiere al nivel de instrucción, el $84,5 \%$ de la población nacional no sabía leer ni escribir, mientras que el $13,5 \%$ sabía leer y escribir y el restante $2 \%$, solo sabía leer. Del total de la población que no sabía leer ni escribir, el 47,5\% eran hombres y $52,5 \%$ eran mujeres. A nivel departamental, Apurímac y Puno tenían una población mayoritariamente analfabeta ${ }^{20}$, mientras que la población con mayor educación se concentraba en el Callao y Lima, las cuales contaban con menor población indígena a nivel nacional. El gran porcentaje de analfabetismo alcanzado de acuerdo al censo, muestra la poca difusión de la educación en el país.

\footnotetext{
16 Decreto del 3 de diciembre de 1854.

17 En los primeros años, los chinos fueron empleados para la agricultura, para la explotación del guano y como servidumbre urbana.

${ }^{18}$ Los culíes sufrieron de malos tratos en las haciendas y vivían en condiciones deplorables, por lo que la mayoría de ellos moría o se suicidaba. Con el episodio de 1872 ocurrido en la embarcación "María Luz" que llevaba al Perú culíes desde Macao, se armó un escándalo que llegó a nivel internacional pues en su escala a Japón, un chino se escapó de la nave y se refugió en un buque británico denunciando los malos tratos producidos en la embarcación "María Luz". Por esto, las autoridades japonesas embargaron la nave y su tripulación. A partir de este hecho, Perú tuvo que modificar sus leyes de inmigración y envió una misión diplomática a fines de 1872 a cargo del señor Aurelio García y García, pero a pesar de esto, el 27 de diciembre de 1873, la colonia inglesa de Macao oficializó el cierre de la emigración de culíes chinos.

${ }_{19}$ El tratado de Tientsin fue de emigración y comercio, denominado "Tratado de Amistad, Comercio y Navegación entre Perú y China” en el cual se incluyeron puntos referidos a la protección de culíes y emigrantes futuros.

${ }^{20}$ Se considera analfabeta a la persona que no sabía ni leer ni escribir según el censo de 1876.
} 
Gráfico 3. Nivel de analfabetismo según el censo de 1876 (En \%)

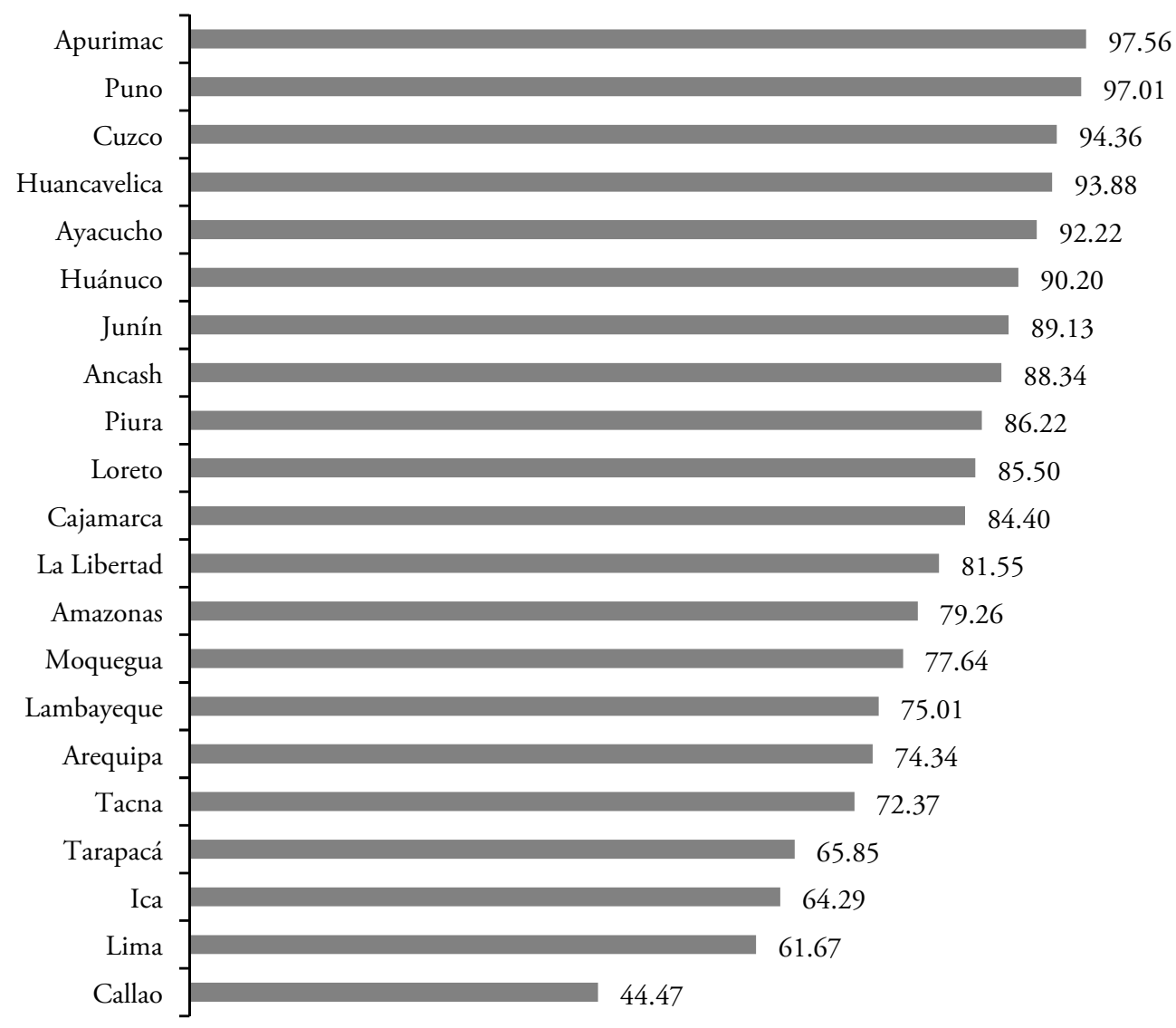

Fuente: Elaboración propia sobre la base del Censo de 1876.

Sin embargo, es importante destacar los esfuerzos que se hicieron en este campo a partir de la mitad del siglo XIX, como el de Ramón Castilla, quien contribuyó en la organización de la enseñanza por medio del Reglamento de Instrucción Pública ${ }^{21}$ de 1850, en el que se precisa que es competencia del Estado la dirección y administración de la vida escolar, clasificando a la educación en pública y privada. Más adelante, el 1 de mayo de 1869, se crea el Concejo Superior de Instrucción Pública y al año siguiente fue dispuesto el funcionamiento de escuelas primarias gratuitas en todas las capitales de distrito (Contreras, 1996, p. 10). Posteriormente, bajo el gobierno de Manuel Pardo se crea la

${ }^{21}$ Reglamento establecido el 14 de junio de 1850. Dividido en 10 capítulos y 67 artículos en el que se divide la organización de la educación pública en tres grados (escuelas, colegios menores y colegios mayores y universidades) y sienta las bases para su desarrollo, teniendo como principio la educación integral del individuo. 
Ley Orgánica de Municipalidades ${ }^{22}$ (1873) que otorga a los Consejos Departamentales, entre otras funciones, el manejo de las escuelas junto a un subsidio proveniente del gobierno central para su financiamiento. Finalmente, el 18 de marzo de 1876, se promulgó el nuevo Reglamento General de Instrucción Pública que organiza la instrucción media. No obstante, a pesar de diferentes esfuerzos enfocados hacia la mejora de la organización de la educación, para 1876 no se produjo una gran revolución en este sector como la que vino a darse a principios del siglo XX con el civilismo en el poder.

\section{METODOLOGÍA DE LA CLASIFICACIÓN DE INGRESOS A PARTIR DEL CENSO DE 1876}

El Censo General de la República del Perú formado en 1876 fue considerado el primer censo elaborado con cifras oficiales de la República. Según Gootenberg, "el Perú no logró realizar un genuino censo nacional sino hasta medio siglo después de la independencia, en 1876" (1995, p. 6).

El censo de 1876 rescató con mayor precisión la composición de la población pues recogió minuciosos datos laborales, sociales y regionales. Entre las características investigadas en el censo se encuentran: raza, sexo, religión, nacionalidad, edad, nivel instrucción (si saben leer y escribir), propiedad y ocupación.

La principal variable que he considerado en el análisis fue la de ocupaciones, pues en ella se encuentran listados los diversos oficios que eran desempeñados por la población económicamente activa de cada distrito. Además las ocupaciones se encuentran detalladas por sexo y nacionalidad, de esta forma cada ocupación describía cuántos hombres y mujeres, nacionales o extranjeros, ejercían dicho oficio. Lamentablemente, el nivel de desagregación no fue más allá que aquella descripción, pues no se encontraron relaciones con otras variables que permitan establecer otras asociaciones como, por ejemplo, los rangos de edad de las personas agrupadas por ocupaciones o, la raza a la que pertenecía cada trabajador, pues como se sabe, las diferencias étnicas eran uno de los más importantes determinantes en la desigualdad de ingresos.

Para el análisis de datos, utilicé las ocupaciones agrupadas por provincias y hallé un total de 337 oficios a nivel nacional. Dada la cantidad de oficios hallados y, para efectos del cálculo de ingresos, elaboré categorías ocupacionales que agruparon a trabajadores con las mismas perspectivas de ingresos salariales de acuerdo al nivel

\footnotetext{
22 Dentro del programa de descentralización de Manuel Pardo, se establece la Ley de Municipalidades que dividió al Estado en cuatro niveles: nacional, departamental, provincial y distrital y creó los consejos departamentales, provinciales y distritales. Esta ley otorgó a los consejos departamentales y provinciales, el servicio de la instrucción pública, el mantenimiento y erección de obras públicas en la circunscripción, la atención hospitalaria y de beneficencia, el registro civil, y otras funciones.
} 
de especialización obtenido. De esta forma, agrupé a la fuerza laboral en siete grandes categorías $^{23}$ (ver anexo 4):

1. Profesionales: esta categoría abarca a las personas que alcanzaron estudios superiores, por lo cual cuentan con altos salarios.

2. Empleados: trabajadores que ejercían un cargo público que exigía cierta educación, como los amanuenses, dado que recibían un sueldo estable que les permitía vivir cómodamente.

3. Técnicos artesanos: trabajadores independientes que utilizaban mucha destreza en el proceso de creación de bienes o quienes, cuya labor, haya implicado un proceso de aprendizaje con cierto grado de complejidad tales como los plateros, alfareros, sastres, zapateros, entre otros.

4. Agricultores: este grupo ya se encontraba definido como tal en el censo, además se le sumó el grupo de los labradores, dado que ambos términos son usados como sinónimos para definir a la persona que trabaja la tierra.

5. Obreros: trabajadores dependientes que no necesitaban obtener altas calificaciones para desempeñarse como tal, ya que el proceso de aprendizaje no era complicado. Dentro de este grupo se encontraban los operarios y peones.

6. No calificados: trabajadores independientes con ingresos bajos y no estables. Las personas en este rubro se caracterizan por no tener algún nivel de instrucción y, si lo tenían, era muy bajo. De esta forma, la categoría estaría representada por fruteros $^{24}$, alfalferos ${ }^{25}$, aguadores, entre otros.

7. Oficios femeninos de remuneración baja: compuesto por mujeres que ejercían el oficio de hilanderas, tejedoras, cocineras, lavanderas, etc., y que se caracterizaba por obtener un bajo nivel de ingresos.

Para la asignación de salarios (ver anexo 5) utilicé como una de las fuentes principales al Presupuesto General de la República 1875-1876, dado que se encontraban detallados los ingresos anuales de los puestos de las autoridades del gobierno, así como de las autoridades departamentales y de algunos empleados públicos.

Para el caso de un profesional, elaboré un promedio a partir de datos provenientes del Presupuesto del Concejo Departamental de Lima para el bienio de 1876-1878, sin embargo, dado que no se publicaron datos del ingreso de un profesional para el resto del país, elaboré una proporción de sueldos de los prefectos — del Presupuesto General—

\footnotetext{
${ }^{23}$ En el siguiente capítulo se elabora otra estimación suponiendo una categoría más alta que engloba a los patrones y/o empresarios.

${ }^{24}$ Persona que se dedicaba a vender fruta.

25 Se presume que eran los que se dedicaban a vender alfalfa.
} 
por cada departamento respecto a Lima, de esta forma obtuve índices por región con lo cual generé salarios diferenciados por departamento ${ }^{26}$.

En el caso del salario de los empleados, utilicé el Presupuesto del Concejo Departamental de Lima y del Concejo Provincial de Tarapacá para el bienio de julio de 1876 a junio de 1878, pues se detallan los salarios anuales destinados a diferentes puestos de las instancias de los concejos en cada caso. Para obtener el salario anual en el resto de departamentos, empleé los datos del Presupuesto General para el bienio de 1875-1876, pues se detallaron los ingresos anuales de los puestos de los empleados en cada prefectura del país.

Por otra parte, los salarios asignados para la categoría de técnicos/artesanos y obreros los obtuve de Salinas ${ }^{27}$ (2013), pues muestra los jornales ${ }^{28}$ de distintas ocupaciones para diferentes provincias a nivel nacional. Sin embargo, dado que no se encontraron datos detallados para todos los departamentos del Perú, utilicé un sistema de proporciones en base a las categorías salariales ${ }^{29}$ de 1866, publicadas por J. M. Rodríguez (ver anexo 6); dichas categorías se elaboraron con el fin de asignar precios de jornales ${ }^{30}$ diarios por provincia, y así obtener un esquema de recaudación de impuestos más justa y proporcional a los ingresos de los jornaleros respecto a su ubicación geográfica.

Para calcular el ingreso de los agricultores ${ }^{31}$, tomé como fuentes primarias a Salinas (2013) y a las memorias de los subprefectos de diferentes provincias publicadas en el diario oficial El Peruano entre 1874 y 1876.

Asimismo, el salario para los trabajadores no calificados lo calculé a partir del ingreso anual de los sirvientes de Lima según el Presupuesto del Concejo Departamental de Lima. Y tal como en el caso de los técnicos/artesanos y de los obreros, apliqué las mismas proporciones con el fin de obtener el ingreso anual promedio de un no calificado por departamento.

${ }^{26}$ La literatura nos muestra que los salarios en el Perú del siglo XIX se diferenciaban de acuerdo a la ubicación geográfica. Los salarios de la costa eran mayores a los de la selva y estos a los de la sierra. Por lo general, los salarios de las capitales departamentales eran mayores en comparación al resto de provincias.

27 Historiador formado en la Universidad Nacional Mayor de San Marcos e investigador del Seminario de Historia Rural Andina de la misma institución. Autor de numerosas publicaciones sobre la historia económica del Perú.

${ }^{28}$ Se describen los jornales para distintos ańos del siglo XIX, pero se tomaron los descritos para el periodo $1874-1876$.

29 Si bien la información es de una década anterior a la analizada en este estudio, las categorías publicadas por Rodríguez son importantes en tanto permite conocer el promedio del jornal de un trabajador de cada provincia del Perú. Además, se asume que la diferencia en las perspectivas salariales de cada provincia no experimentó algún cambio drástico hasta 1876.

30 Se agruparon a las provincias según el precio del jornal, para el cual se dividió 6 categorías (de 0,20 a 0,80 centavos). En algunos casos, el precio del jornal se encontraba generalizado por departamento, pero para otros casos, existió información de los jornales en más de una provincia de un departamento por lo que elaboré un promedio ponderado usando las variables: jornal provincial y pea provincial. Así se obtuvo el índice promedio del salario de un departamento.

${ }^{31}$ Los jornales encontrados por departamento se encontraban diferenciados por provincia por lo que se hizo un promedio ponderado con las variables: jornal provincial y PEA de agricultores de la provincia. De esta forma se generalizó el jornal departamental. 
Finalmente, el salario para la categoría de oficios femeninos de remuneración baja lo estimé como las tres cuartas partes del ingreso de un no calificado, pues la diferencia de ingresos no solo se produjo a nivel regional, sino que el sexo era un factor importante en la asignación de salarios. Recordemos que el nivel de educación de la mujer en el siglo XIX era menor al promedio de los hombres y no contaban con los mismos derechos, por lo que en el ámbito laboral, dichas diferencias también se aplicaban a los ingresos. Por esto, en la categoría de los agricultores y obreros, hice una división previa a la población por sexo, y al jornal femenino le asigné las tres cuartas partes del salario agricultor u obrero, calculado previamente según sea el caso.

Cabe mencionar que la gran limitación para este estudio fue hallar fuentes oficiales sobre el salario para diferentes ocupaciones, a pesar de ello, traté de calcular con mayor detalle los ingresos anuales de las diferentes categorías ocupacionales por departamento. A continuación se muestran algunas distribuciones que estimé en base al censo de 1876, agrupadas por categorías laborales.

Gráfico 4. Distribución de trabajadores a nivel nacional por categoría laboral según el censo de 1876

(En \%)

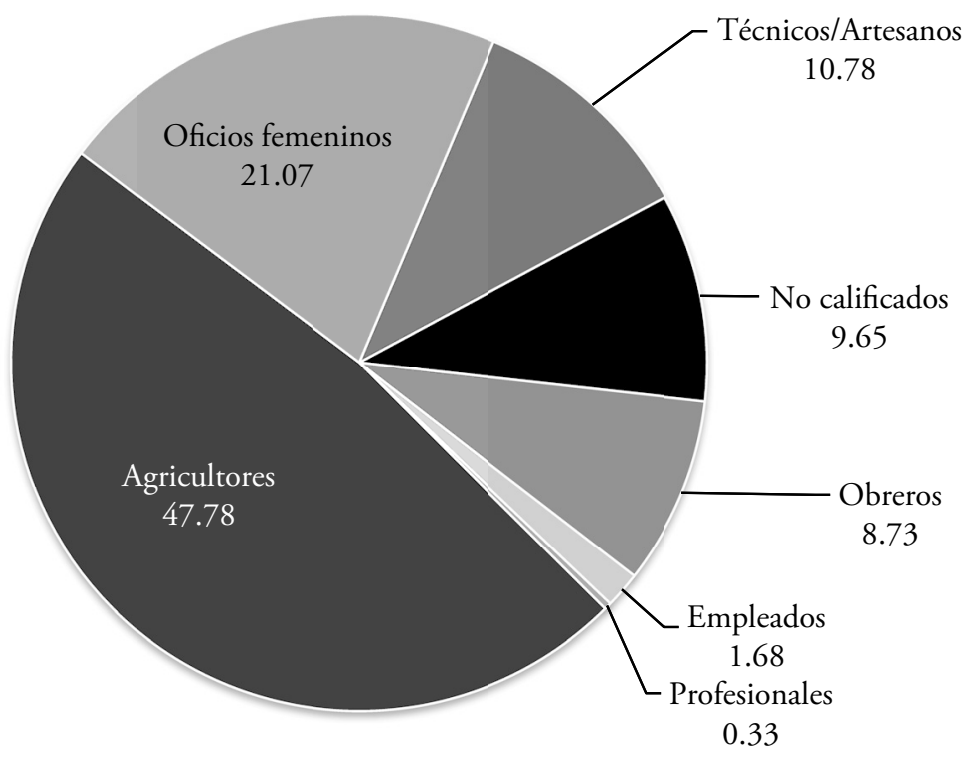

Fuente: Elaboración propia sobre la base del censo de 1876. Ver anexo 4.

La fuerza laboral tuvo mayor concentración en el sector agrícola con una participación de $47,78 \%$, seguida de los oficios femeninos con $21,07 \%$. Por el contrario, las categorías de los profesionales $(0,33 \%)$ y empleados $(1,68 \%)$, contaron con una mínima presencia en la población laboral. El departamento cuya población era mayoritariamente 
agrícola es Huancavelica, con un 80,3\%, seguido de Apurímac (67,5\%); lo opuesto se manifiesta en la provincia constitucional del Callao $(2,6 \%)$ y la provincia litoral de Tarapacá (17,4\%), pues dichas localidades acogieron a la mayor cantidad de población que se dedicaba al comercio, así como a la explotación de los recursos del mar, en el primer caso y a la explotación del mineral salitre, en el segundo. Por ello, era de esperarse que ambas provincias no albergaran a tanta población agrícola, a diferencia de los departamentos cuyo territorio era más propicio para dicha actividad.

Gráfico 5. Distribución de los agricultores por departamentos, 1876

(En \%)

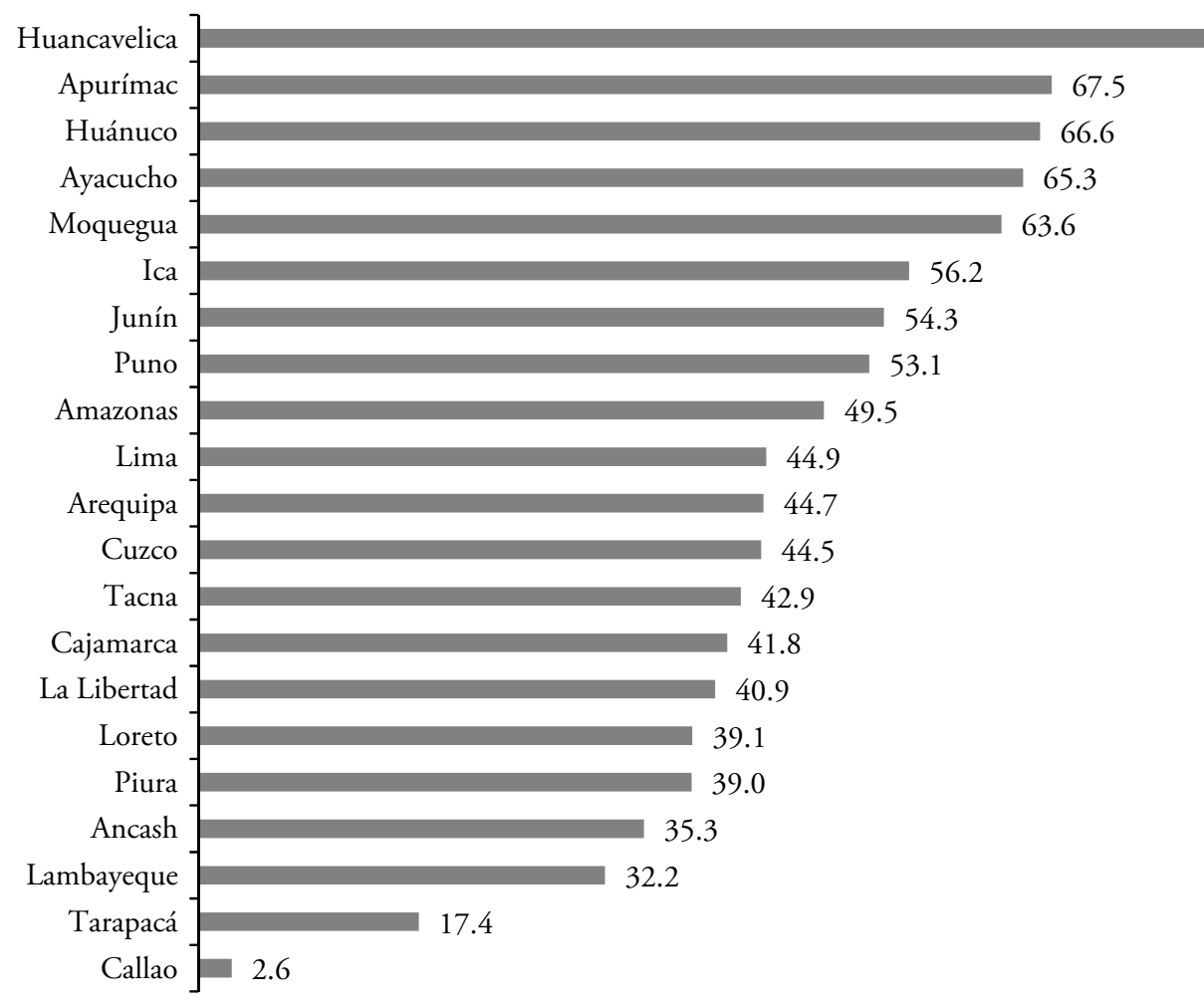

80.3

Fuente: Elaboración propia sobre la base del Censo General de la República de 1876.

Por otro lado, la categoría laboral que menor participación tuvo a nivel nacional fueron los profesionales, dado que solo se pudo contabilizar a 4297 de los cuales el 31\% se concentró en Lima, pues el nivel de educación en la capital era mucho mayor que en el interior del país. Cabe mencionar que entre Lima, Arequipa, La Libertad y Cuzco, se concentró cerca del 60\% de población profesional en el Perú. 
Gráfico 6. Distribución de los profesionales a nivel nacional, 1876

(En \%)

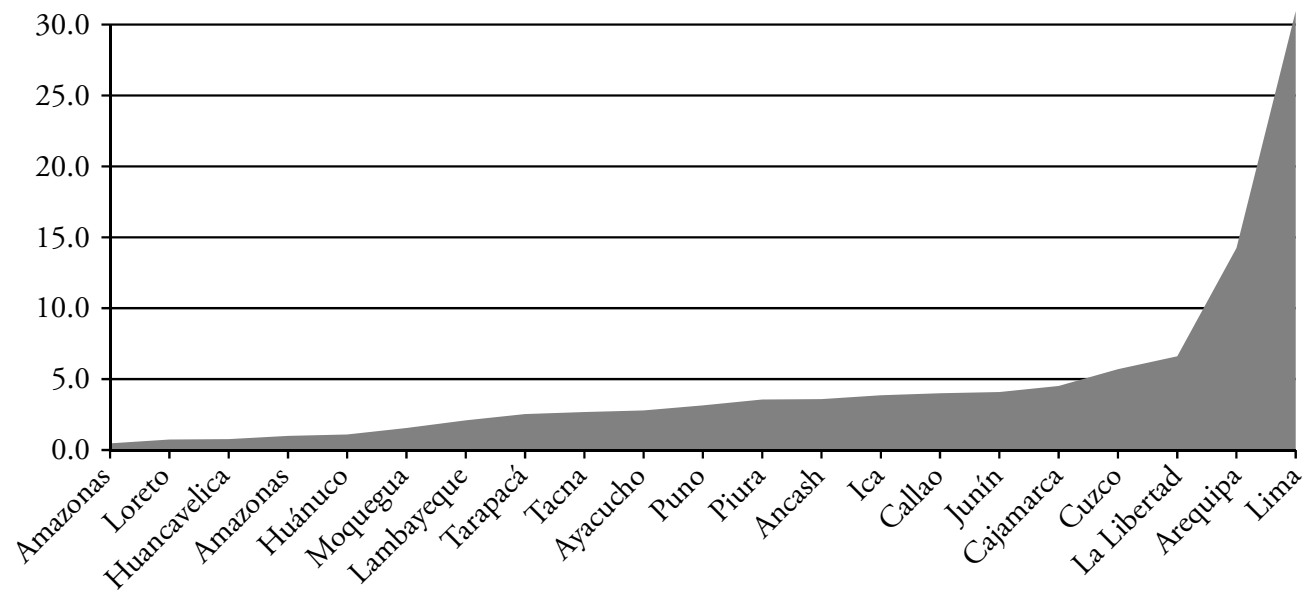

Fuente: Elaboración propia sobre la base del Censo General de la República de 1876.

Finalmente, del total de la población económicamente activa a nivel nacional, Puno concentró al 12\% de esta, seguido de Áncash (11\%), Cuzco (9\%) y Lima (8\%). Para estos cuatro departamentos, la población agricultora constituyó más del $40 \%$ de la fuerza laboral exceptuando a Áncash, donde los datos sugieren que los oficios femeninos habrían ocupado la mayor cantidad de fuerza laboral en el departamento, superando ligeramente a los agricultores. La existencia de una mayor PEA femenina podría explicarse por la composición de la población, pues el 52\% eran mujeres; cifra relativamente alta, si comparamos la población femenina del resto de los departamentos.

Cuadro 1. Población económicamente activa por departamento, 1876

\begin{tabular}{lr}
\hline \multicolumn{1}{c}{ Departamento } & $\mathrm{N}^{\circ}$ de personas \\
\hline Amazonas & 19176 \\
Áncash & 144582 \\
Apurímac & 42971 \\
Arequipa & 82489 \\
Ayacucho & 83071 \\
Cajamarca & 94278 \\
Callao & 13787 \\
Cuzco & 119817 \\
Huancavelica & 45907 \\
Huánuco & 34164 \\
Ica & 28824 \\
\hline
\end{tabular}

\begin{tabular}{lr}
\hline Departamento & $\mathbf{N}^{\circ}$ de personas \\
\hline Junín & 101813 \\
La Libertad & 59154 \\
Lambayeque & 33798 \\
Lima & 103107 \\
Loreto & 27128 \\
Moquegua & 19022 \\
Piura & 62894 \\
Puno & 153200 \\
Tacna & 18528 \\
Tarapacá & 24639 \\
Total & 1312349 \\
\hline
\end{tabular}

Fuente: Elaboración propia. Censo de 1876.

La población económicamente activa según el censo de 1876, representó el 48,6\% del total de la población en el Perú. 


\section{RESULTADOS}

Para estimar el grado de desigualdad en la distribución de los ingresos por categorías laborales, utilicé el coeficiente de Gini ${ }^{32}$. Así, obtuve los siguientes coeficientes departamentales para 1876.

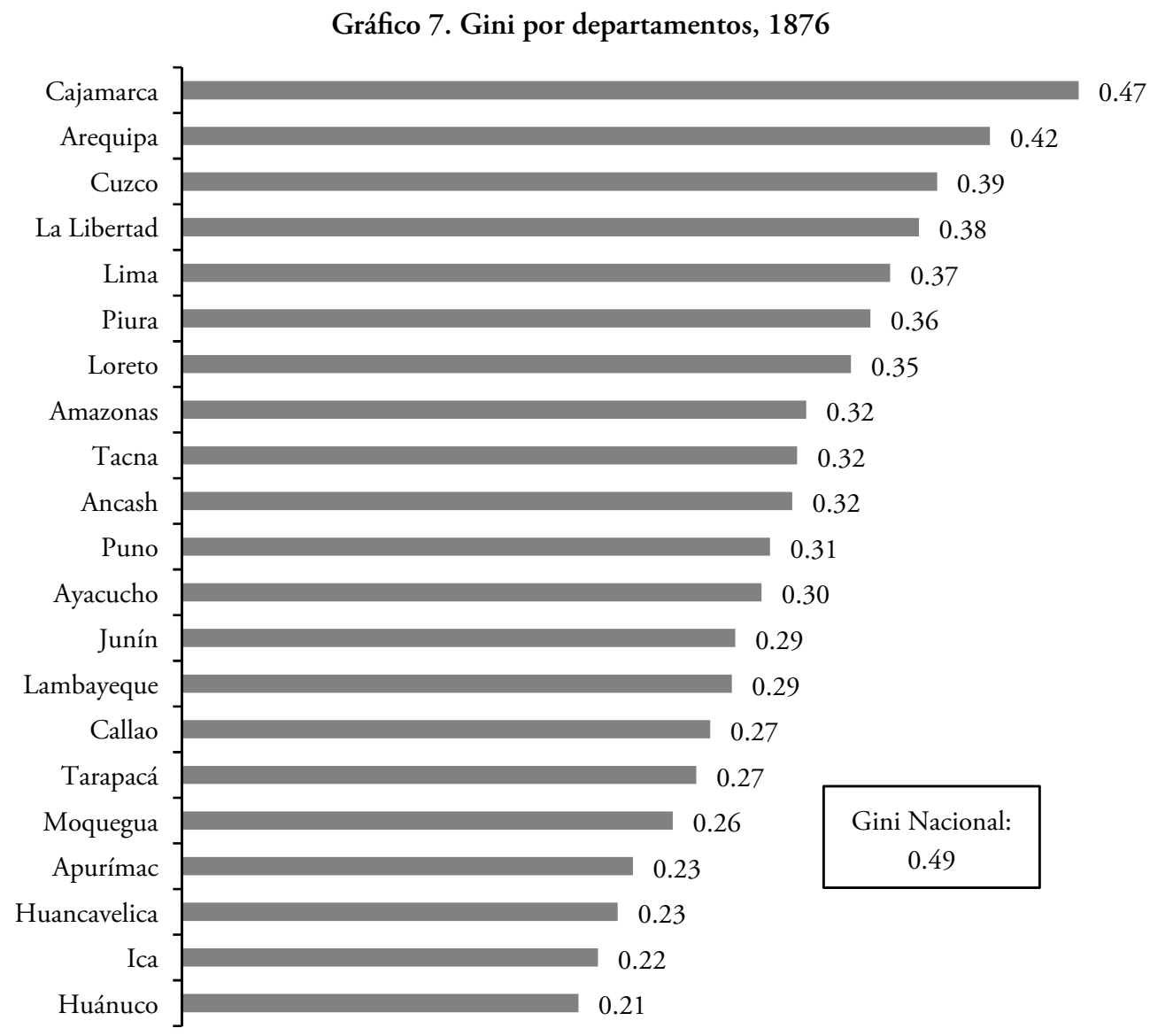

El departamento con el mayor nivel de desigualdad de ingresos salariales es Cajamarca $(0,47)$ y puede ser explicado, en parte, por la composición racial de la población pues el $28 \%$ estaba compuesto por blancos, cifra bastante alta en comparación con el resto del país, además, la población india del territorio no fue tan significativa como en el resto de departamentos ${ }^{33}$. Se sabe que para aquella época las razas determinaban, en gran medida,

32 Este índice se mide entre un rango de 0 a 1 , en el que 0 significa un nivel de igualdad perfecta, mientras que el 1 implica un nivel alto de desigualdad.

${ }^{33}$ Los departamentos con menor población india en el Perú según el censo de 1876 fueron el Callao, Cajamarca y La Libertad pues su participación fue de 24\%, 35\% y 39\% respectivamente, por el contrario, el resto de departamentos tuvo una población india mayor al $40 \%$ del total de habitantes. 
la posición económica que uno lograba, por lo que la mayoría de indios estaba destinada al trabajo en el campo, mientras que las personas de raza blanca alcanzaban altos cargos, debido al acceso a la educación de la que gozaban. El ingreso calculado para los agricultores en Cajamarca, casi en su totalidad indios, es uno de los más bajos del Perú al igual que el alcanzado por las mujeres.

Una figura parecida se produce en Arequipa, en lo que se refiere a la composición racial de la población; además, el número de profesionales presentes fue uno de los más significativos a nivel nacional.

Por el contrario, Huánuco presentó el menor nivel de desigualdad en el país, pues la población económicamente activa estuvo concentrada en la agricultura mientras que los profesionales y empleados se encontraban lejos de ser significativos en la muestra y sus ingresos se encontraban entre los más bajos del país. Por esto, no existió un grupo que concentrara la mayoría de los ingresos salariales en este departamento.

En el caso de Ica, el 55\% de la población era indígena y albergó a la mayoría de inmigrantes negros y chinos que fueron destinados como mano de obra para las haciendas azucareras y para las islas guaneras, respectivamente. El grupo formado por los profesionales y empleados fue minoritario.

Asimismo, el bajo nivel de desigualdad estimado para Huancavelica se debe a la gran cantidad de raza india presente, pues llegó a componer el 79\% de la población total. Además, la fuerza laboral se concentró en la agricultura ( $80 \%$ de la PEA), por el contrario, la población de mayores ingresos llegó a alcanzar cerca del $0,4 \%$ de la población laboral.

En general, los niveles del coeficiente de Gini departamentales que estimé para 1876 no muestran un gran nivel de desigualdad dentro de cada territorio, sin embargo, a nivel nacional el coeficiente se eleva a 0,49 lo que demuestra las diferencias regionales existentes en el país. No obstante, este resultado es mucho menor a los estimados a lo largo del siglo XX, por lo que se puede inferir, así como lo hicieron Gootenberg y Contreras, que la gran mayoría de indígenas en la población peruana fue un factor que habría mantenido un bajo nivel de desigualdad hasta finales del siglo XIX. Cabe recordar que para el periodo 1791-1876 no se produjo un cambio trascendental en la composición de la población indígena peruana, por tanto, las ocupaciones tampoco habrían experimentado grandes cambios. Por otro lado, es importante mencionar que la principal fuerza laboral del país la conformó los agricultores, quienes recibían bajos jornales. Además, el grupo con mayores ingresos (profesionales), tuvo poca presencia al interior del país ${ }^{34}$.

\footnotetext{
${ }^{34}$ La presencia de los profesionales se limitó a las principales ciudades de cada departamento. La selva y sierra fueron los territorios con menor cantidad de esta categoría. Excepto por Cuzco, Cajamarca y Arequipa donde sí existió un mayor número de profesionales en comparación al resto de la sierra.
} 


\subsection{UNA SEGUNDA APROXIMACIÓN A LA DISTRIBUCIÓN DE INGRESOS}

Si bien los resultados presentados están basados en las siete categorías laborales que fueron descritas en el capítulo anterior, es importante destacar que existió una categoría más alta que la de los profesionales, pues correspondería a los grandes empresarios, dueños de industrias florecientes en aquella época así como los dueños de minas, salitreras y hacendados. Sin embargo, en la descripción de oficios en el censo de 1876 no se describen aquellos puestos de manera explícita y existe la posibilidad que este grupo de personas no haya sido incluido en los datos del censo. Bajo esta premisa, en un intento de calcular la distribución de ingresos incluyendo a esta nueva categoría, a la que llamaremos "patrones/empresarios", recurrí a diversas fuentes con el fin de obtener la cantidad de industrias, minas y demás, que existieron en el año analizado y así aproximar la cantidad de personas pertenecientes a la categoría ${ }^{35}$.

En el caso de los hacendados, los datos los obtuve del número de haciendas existentes por provincia (ver anexo 7) pues se asume que cada una de estas tenía a la cabeza a una persona dueña de la estancia y, por lo tanto, la manejaba. Para hallar el número de haciendas, utilicé el "Resumen del Censo General de Habitantes del Perú hecho en 1876", en donde se contabilizaron 4470 haciendas a nivel nacional.

Para aproximar la cantidad de empresarios mineros, la información más cercana a la época la obtuve de la "Estadística de las minas de la República del Perú de 1878" elaborada por la Dirección de Estadística del Perú; en este documento se contabilizó el número de minas trabajadas por empresas y por particulares en cada distrito mineral del país. En total, estimé 1320 empresarios mineros a nivel nacional.

Por otra parte, si bien las salitreras empezaron a expropiarse en 1876, es importante incluir a los empresarios salitreros de la época pues no fue sino hasta 1878 cuando casi la totalidad de las oficinas fueron compradas por el Estado. Asumiendo que aún en 1876 la totalidad de oficinas salitreras seguían en manos de particulares, estimé a un total de 96 empresarios salitreros. La fuente de los datos fue la "Memoria especial presentada al Congreso Extraordinario de 1876 por el Ministro de Hacienda y Comercio, Juan Ignacio Elguera”.

Asimismo, uno de los grupos relevantes para esta categoría lo conforman los industriales y, en este caso en particular, no existió fuente oficial que los contabilizara dado que la industria en el país no estaba aún desarrollada y no existió padrón alguno que los agrupara. Sin embargo, uno de los autores más importantes que describió la situación de este sector a finales del siglo XIX fue Alejandro Garland en su "Reseña Industrial del Perú" publicada en 1905, pues describe las diferentes industrias que ya funcionaban en aquella época como las fábricas de tejidos de algodón, las fábricas de chocolate, las fidelerías, entre otras. Para conocer el año de fundación de las diferentes industrias

35 Ver anexo 8. 
utilicé, como fuentes primarias, la Estadística Industrial del Perú de 1922 elaborada por el Ministerio de Fomento, así como también los datos encontrados en Garland. No obstante, no fue posible encontrar los años de fundación para todas las industrias analizadas así que para ciertos subsectores, asumí que la cantidad existente para 1876 fue la mitad de lo descrito para fines del siglo XIX. Con todo, Lima fue la provincia que aglomeró al mayor número de industriales en el país, en parte al gran porcentaje de extranjeros que habitaron la capital (ver anexo 9). Monsalve (2011, p. 251) menciona que con la llegada de inmigrantes europeos se fortaleció el mercado urbano al ser estos los responsables de fundar y gestionar nuevas fábricas.

La asignación del ingreso ${ }^{36}$ para esta categoría fue difícil en tanto no encontré alguna fuente que señalara el ingreso de un empresario de 1876, por esta limitación de información, usé como parámetro ${ }^{37} \mathrm{el}$ salario anual de un ministro, pues era una de las más altas autoridades del gobierno y los segundos con mayor sueldo después del presidente, de acuerdo al Presupuesto General de 1875-1876. Para asignar el salario por departamentos utilicé la misma proporción estimada para hallar el salario de los profesionales.

Finalmente, los resultados obtenidos muestran una tendencia similar del nivel de desigualdad a nivel nacional en comparación con la primera estimación.

Como se observa, el departamento con mayor nivel de desigualdad (Cajamarca) y el de menor desigualdad (Huánuco) ocupan el mismo lugar que en la estimación anterior. Mientras que los departamentos que experimentaron los mayores cambios fueron Huancavelica, Junín, Loreto y Lima. En el caso de Huancavelica, la razón por la cual aumentó el nivel de desigualdad en comparación a la anterior estimación, se puede explicar por el gran número de hacendados incluidos en este análisis, ya que a nivel nacional, Huancavelica fue el tercer departamento con mayor número de haciendas. A pesar de que no había industria, existió un pequeño grupo de empresarios mineros que también afectó la distribución de los ingresos. Respecto a Junín, se estimó un índice mucho mayor porque al igual que en Huancavelica, el número de hacendados era muy significativo en el territorio, a lo que se agregó la cantidad de empresarios mineros que se concentraron en la región. El número de estos fue superior al de los demás departamentos. En lo que respecta al caso de Lima, la distribución de ingresos empeoró por la cantidad de haciendas, empresarios mineros e industriales, que albergó la capital. Sobre todo se debió a la cantidad de los industriales que se establecieron en Lima, pues fue el territorio con la mayor cantidad de este grupo a nivel nacional. Cabe recordar que la llegada de inmigrantes europeos dinamizó el mercado urbano y se logró fortalecer la industria poco a poco.

\footnotetext{
36 Ver anexo 8.

37 Se consideró el $75 \%$ del salario de un ministro para un empresario limeño, pues cabe acotar que no todos eran grandes empresarios, sino que también existían dueños de pequeñas industrias, cuyos ingresos no serían tan elevados. A partir del salario calculado para Lima, se calcularon los departamentales.
} 
Gráfico 8. Gini por departamentos, 1876

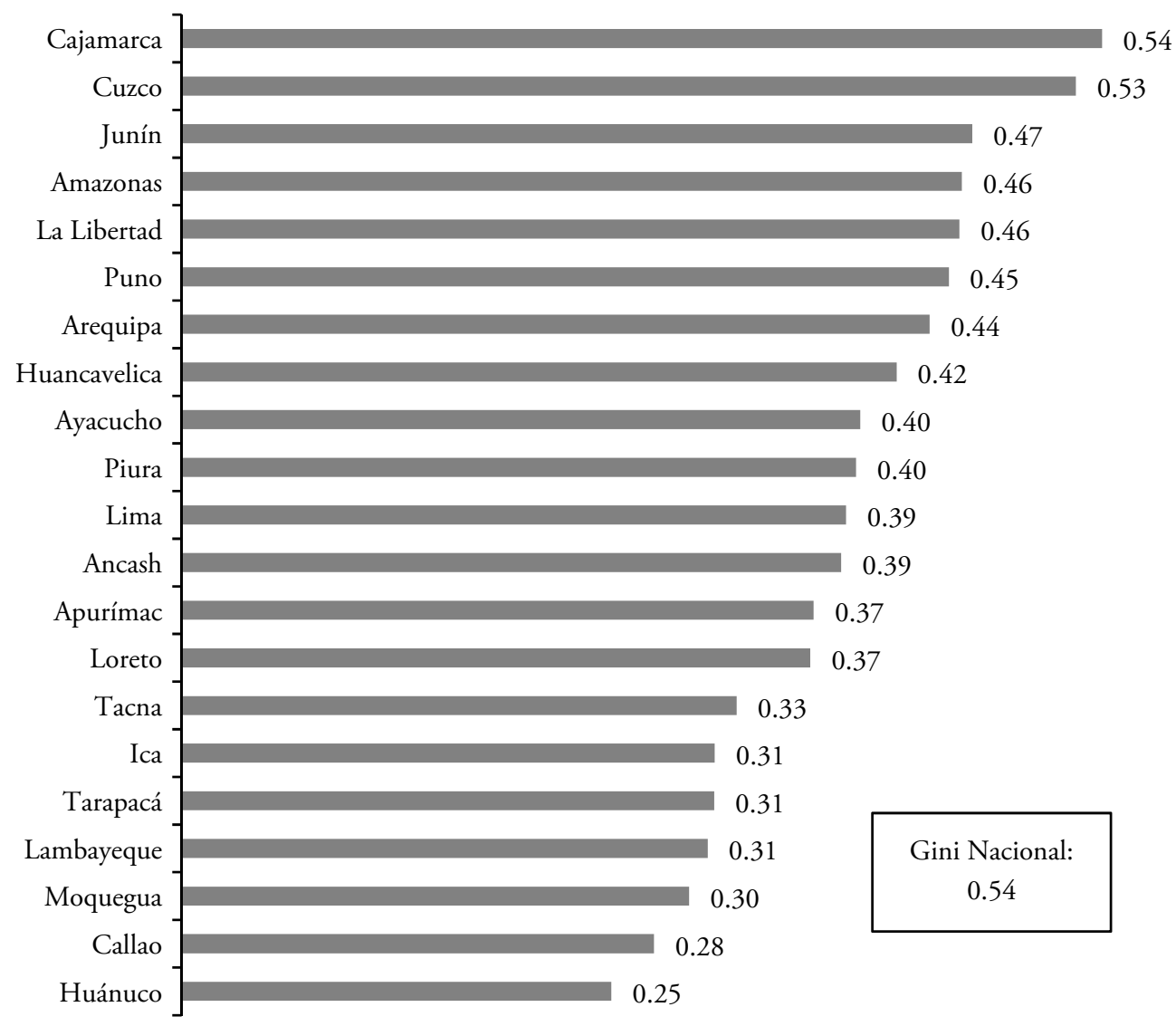

Lo contrario sucedió con Loreto, en donde la nueva estimación de desigualdad disminuyó significativamente. En este caso la población empresaria fue mínima y el salario asignado para esta clase fue uno de los más bajos del país, además, la fuerza laboral se concentró en las ocupaciones de menor salario lo que hizo más homogénea la distribución.

En general, se observa que al incluir una categoría más alta que agrupa a los empresarios/patrones, la distribución del ingreso varía significativamente en algunos departamentos. Asimismo, el Gini nacional calculado aumenta de 0,49 a 0,54 lo cual indica que en el Perú de 1876, la desigualdad pudo haber sido mayor a lo esperado. Sin embargo, en esta sección, los cálculos hechos no pueden ser considerados como concluyentes, pues como se mencionó anteriormente, los datos tomados para armar esta categoría son aproximaciones de la verdadera cantidad existente de empresarios en 1876. A pesar de las limitaciones de los datos, esta nueva estimación puede darnos un mayor alcance del nivel de desigualdad, tal vez, más cercano a la realidad de la época. 


\section{DESIGUALDAD EN AMÉRICA LATINA DEL SIGLO XIX}

Durante años ha existido un intenso debate sobre las raíces de la desigualdad en América Latina, sin embargo parece ser que dicho fenómeno se acentuó desde los inicios del siglo XIX cuando la mayoría de las colonias atravesaba el proceso de independencia, pues las luchas por ella fracturaron las sociedades coloniales entre las élites comerciales que estaban a favor de las ideas capitalistas y los sectores más tradicionales, defensores del ancestro español y de la religión. Más adelante, hacia finales del siglo, la mayor apertura hacia el comercio internacional habría afectado aún más los niveles de desigualdad en la región.

La raíz del retraso de América Latina podría contextualizarse en la Revolución Industrial, pues esta produjo una transformación en la economía capitalista de los países europeos que originó un proceso de aceleración en el cambio tecnológico. Este fenómeno marcó la distancia en la brecha de crecimiento entre los países industrializados y los de América Latina. En este sentido, Angus Maddison ${ }^{38}$ realiza estimaciones del PBI per cápita desde el siglo XIX para algunos países de América Latina, América del Norte y Europa. De acuerdo a las cifras, la brecha de crecimiento del PBI per cápita de los países industrializados se empieza a acentuar en el siglo XIX y sufre un gran despegue en el XX.

Por otro lado, en la publicación Décadas perdidas de Bates, Coatsworth y Williamson (2007), se señala que durante el periodo independentista de las colonias, América Latina se envolvió en violencia entre 1820 y 1870, lo cual ocasionó grandes costos que generaron persistentes crisis fiscales. Los autores mencionan que medio siglo después de que estos países lograran su independencia, el desarrollo económico se vio estancado tanto para la región como para países africanos. Para los autores, la época denominada "décadas perdidas" tuvo una larga duración porque las fuerzas liberales poscoloniales fueron resistidas por la existencia de poderosas élites de colonos que aún ejercían liderazgo en colonias como México y Perú. Estas élites se resistían al cambio porque sus intereses se interconectaban con el régimen imperial. De esta forma, las restricciones sobre la actividad económica existentes, impidieron el desarrollo de una clase económica lo suficientemente fuerte para derrumbar los privilegios de la élite colonial. No obstante, las causas de la divergencia económica de las regiones luego de la crisis colonial son múltiples. Las guerras fueron un factor que causaron efectos negativos sobre la economía; la destrucción de recursos humanos y capital físico de actividades tradicionales fue lo más difícil en recuperar.

Existen muy pocos datos disponibles sobre la distribución del ingreso para los países de América Latina en el siglo XIX, no obstante, en el trabajo realizado por Bértola,

\footnotetext{
38 Economista inglés que lideró la División de Economía de la OEEC (Organization for European Economic Cooperation) que luego se transformó en la OECD (Organization for Economic Cooperation and Development). Fue el pionero en la construcción de series históricas de las cuentas nacionales de países de todo el mundo.
} 
Castenolvo, Rodríguez y Willebald (2010), se encuentran mediciones de la desigualdad a través del índice de Gini para algunos países de la región. De acuerdo a los autores, el crecimiento de AL se basó en la explotación de recursos naturales con ausencia de cambios tecnológicos, lo cual originó varias limitaciones. Además, si bien los países de América Latina tuvieron mucho en común en el siglo XIX, los países que destacaron en su crecimiento, fueron Argentina y Uruguay.

La estimación de la desigualdad en los ingresos que los autores realizan, se limita a los años 1870 y 1920 para Brasil, Chile, Uruguay y Argentina, que disponían con mayores datos en comparación al resto de la región. Para estimar la desigualdad en el caso de Brasil, se utilizan datos de los censos del año 1872 y 1920 pues en ellos se divide a la población por género y condición, es decir, si son libres o esclavos para diferentes profesiones. Se les asignó rangos de ingresos mediante diferentes fuentes y supuestos.

En el caso de Chile se agrupó a la población de acuerdo a sectores económicos y se utilizaron diferentes fuentes de información para asignar el salario a cada sector. Por otro lado, Uruguay solo tuvo datos disponibles para 1920, en el que se consideró a los funcionarios públicos, a todo el sector agrario y a los trabajadores industriales. Sin embargo, datos para el año 1870 no pudieron ser hallados, por lo que fueron estimados a partir de los de 1920. Finalmente, para Argentina se hicieron muchos supuestos por la escasez de información en aquella época.

Cuadro 2. Desigualdad de ingresos de América Latina para 1870 y 1920

\begin{tabular}{lcc}
\hline \multirow{2}{*}{\multicolumn{1}{c}{ País }} & \multicolumn{2}{c}{ Gini } \\
\cline { 2 - 3 } & $\mathbf{1 8 7 0}$ & $\mathbf{1 9 2 0}$ \\
\hline Argentina & 0,522 & 0,574 \\
Brasil & 0,548 & 0,597 \\
Chile & 0,594 & 0,641 \\
Uruguay & 0,481 & 0,562 \\
América Latina & 0,549 & 0,595 \\
\hline
\end{tabular}

Fuente: Bértola, Castelnovo, Rodríguez y Willebald (2010)

De acuerdo a las estimaciones, Chile es el país con un nivel ligeramente más elevado de desigualdad en $1870 \mathrm{y}$, para 1920 sigue la misma tendencia creciente al igual que los demás países. Desde 1870 el coeficiente de desigualdad continuó aumentando hasta principios del siglo XX, como bien se puede comprobar a través del coeficiente calculado para la región en general que aumenta de 0,549 a 0,595. Este resultado, comparado a mi segunda estimación del Gini Perú (0.54), parece colocarnos ligeramente por debajo del promedio de AL, superando a Argentina y Uruguay. No obstante, cabe resaltar que las estimaciones de Bértola, Castelnovo, Rodríguez y Willebald, son muy diferentes a las realizadas en este trabajo, pues manejan una serie de supuestos más generales 
de los datos, especialmente para el caso argentino. Aun así, resulta válida la comparación de los Ginis presentados para la década de 1870 con el hallado para el Perú, pues nos brinda un parámetro de medición de la región para el siglo XIX.

\section{CONCLUSIONES}

El contexto de los países latinoamericanos en el siglo XIX estuvo caracterizado por la presencia de guerras y cambios en el sistema económico y político a causa del periodo independentista que cada uno atravesó. Dicha inestabilidad produjo que el crecimiento de la región en general se colocara muy por detrás de los países europeos y los del Atlántico Norte, que finalmente se reflejó en un aumento continuo de la brecha del PBI respecto a América Latina.

En el Perú, el Estado independentista que se formó, heredó el elitismo presente en la época colonial. No existían leyes que velaran por igual a toda la población, por el contrario, se seguía beneficiando a una élite privilegiada. No se contó con fuertes políticas públicas que permitieran una mejor distribución de ingresos entre la población, entre ellas el acceso a la educación, que fue un privilegio para pocos y que reforzó la exclusión. Las diferencias raciales fueron las que continuaban marcando la desigualdad en la nación. Según el censo de 1876, el Perú tuvo una población de raza indígena que conformó el 57,6\% de los habitantes, donde la principal ocupación de la fuerza laboral fue la agricultura. Asimismo, cerca del $85 \%$ de la población no sabía ni leer ni escribir pues solo una minoría tuvo acceso a una buena educación, que fueron en su mayoría las personas consideradas de raza blanca.

En la primera estimación del Gini para el Perú de 1876 agrupé a la población económicamente activa descrita en el censo, mientras que en la segunda estimación agregué un grupo más alto de ingresos que no fueron caracterizados como tal en el censo y que surgió en base al supuesto válido sobre la existencia de un grupo de mayor poder económico que era parte de la población peruana pero que no se contabilizaron como tal. En la primera estimación, los coeficientes de Gini por departamentos no mostraron altos niveles de desigualdad, sin embargo, a nivel nacional calculé un índice de 0,49 por lo cual se puede inferir que en el país a finales del siglo XIX, existió cierto nivel de desigualdad en la distribución de los ingresos. Por otro lado, con la segunda estimación el resultado ascendió a 0,54 cifra que parece más cercana a la realidad de entonces dado que consideré al grupo con mayor poder económico de la población. En este sentido, el mayor nivel de desigualdad se explicaría, por la gran brecha existente entre los altos ingresos de la élite comparado al ingreso de un trabajador promedio, en su mayoría, agricultor, y la poca diferencia de salarios alcanzados entre las clases más bajas del país (Milanovic, Lindert y Williamson 2009, p. 18). Además, este índice, contrastado al calculado por Bértola, Castenolvo, Rodríguez y Willebald para América Latina de 1870 $(0,549)$, coloca al Perú dentro del promedio de la región. Estos resultados comprueban 
que a finales de siglo XIX, Perú fue una sociedad con un importante nivel de desigualdad en los ingresos, lo cual va acorde con la hipótesis de los autores antes mencionados para el caso de América Latina, donde sostienen que las sociedades de 1870 ya contaban con un nivel de desigualdad de ingresos que fue aumentando al pasar de siglo.

A mediados del siglo XX, la desigualdad de ingresos aumentó significativamente. Esto demuestra que el nivel de desigualdad en el Perú se mantuvo alto durante aquel siglo, debido a los cambios en la composición de la población y en la política económica del país, en el que también se desarrollaron las industrias y se lograron establecer derechos igualitarios para los excluidos del siglo XIX. La desigualdad de ingresos en el siglo pasado aumentó frente a los profundos cambios experimentados, los cuales crearon una senda de crecimiento económico.

En este sentido, de acuerdo a Kuznets ${ }^{39}$, la desigualdad aumentaría en los inicios del proceso de desarrollo de un país pero al llegar a un nivel alto de crecimiento, esta disminuiría; sin embargo, este no sería el caso del Perú pues como sostiene Webb ${ }^{40}$, el nivel de desigualdad ha ido disminuyendo en el presente siglo, pero el país dista de convertirse en una economía desarrollada. Otro punto de vista lo brinda Farid Kahhat ${ }^{41}$, quien argumenta que efectivamente la teoría de Kuznets no se cumple al caso peruano porque nuestro país se encuentra en un proceso intermedio de desarrollo y de acuerdo a la teoría, en esta etapa el nivel de desigualdad debería ser estacionario, sin embargo, este no se comporta de esa manera, por el contrario, ha venido descendiendo con el pasar de los ańos y no se mantiene estable como bien predice la teoría. Con todo, el debate sobre el crecimiento económico y su relación con el nivel de desigualdad viene desde muchos ańos atrás, pero Kuznets al tratar de explicar que la primera genera una mejor distribución de los ingresos al final de la etapa de crecimiento, parece no cumplirse para el caso peruano ni para muchos de los países latinoamericanos. Lo que sí es común en toda América Latina es que la desigualdad data desde el inicio de la formación de sus estados independientes y para el Perú del siglo XIX, en particular, dicho nivel no fue tan diferente a las estimaciones del presente.

\footnotetext{
39 La teoría de Simon Kuznets (ganador del premio Nobel de Economía en 1971) implica una relación estrecha entre el grado de desigualdad y el capitalismo, pues según sugiere, un nivel bajo de desigualdad se relaciona con un menor desarrollo del capitalismo; por el contrario, en una sociedad capitalista el nivel de desigualdad debería ser alto en un inicio y, con el crecimiento económico, dicho nivel decrecería y produciría una mejor distribución de los ingresos.

40 En un artículo publicado en el diario El Comercio de Lima en mayo del 2014 (“El Perú vs. Kuznets"), Webb menciona que la teoría propuesta por Kuznets no se cumple para el caso peruano.

41 Opinión en un artículo de América Economía (http://www.americaeconomia.com/analisis-opinion/elmundo-versus-kuznets).
} 


\section{ANEXOS}

Anexo 1. Población total en 1876

\begin{tabular}{lcc}
\hline \multicolumn{3}{c}{ Población total según censo de 1876} \\
\hline \multicolumn{1}{c}{ Departamento } & Población & \multicolumn{1}{c}{$\%$} \\
\hline Áncash & 284830 & $10,55 \%$ \\
Puno & 259449 & $9,61 \%$ \\
Cuzco & 243032 & $9,00 \%$ \\
Lima & 225800 & $8,37 \%$ \\
Cajamarca & 212745 & $7,88 \%$ \\
Junín & 209761 & $7,77 \%$ \\
Arequipa & 157046 & $5,82 \%$ \\
La Libertad & 147336 & $5,46 \%$ \\
Ayacucho & 142215 & $5,27 \%$ \\
Piura & 135615 & $5,02 \%$ \\
Apurímac & 118525 & $4,39 \%$ \\
Huancavelica & 103069 & $3,82 \%$ \\
Lambayeque & 86738 & $3,21 \%$ \\
Huánuco & 78991 & $2,93 \%$ \\
Loreto & 61905 & $2,29 \%$ \\
Ica & 60255 & $2,23 \%$ \\
Tarapacá & 38225 & $1,42 \%$ \\
Tacna & 36009 & $1,33 \%$ \\
Callao & 34492 & $1,28 \%$ \\
Amazonas & 34284 & $1,27 \%$ \\
Moquegua & 28785 & $1,07 \%$ \\
\hline Total & 2699107 & $100,00 \%$ \\
\hline He: Cen &
\end{tabular}

Fuente: Censo General de la República de 1876. 


\section{Anexo 2. Razas según el censo de 1876}

Razas identificadas en el censo de $\mathbf{1 8 7 6}$

(Número de personas)

\begin{tabular}{lrrrrrr}
\hline Departamento & Blancos & \multicolumn{1}{c}{ Indios } & Negros & Asiáticos & Mestizos & \multicolumn{1}{c}{ Total } \\
\hline Amazonas & 6825 & 18201 & 9145 & 5 & 108 & 34284 \\
Áncash & 18706 & 132792 & 2453 & 3975 & 126904 & 284830 \\
Apurímac & 14427 & 64681 & 96 & 15 & 39306 & 118525 \\
Arequipa & 49878 & 68056 & 2887 & 1050 & 35175 & 157046 \\
Ayacucho & 18427 & 102827 & 311 & 43 & 20607 & 142215 \\
Cajamarca & 59774 & 73806 & 1051 & 357 & 77758 & 212746 \\
Callao & 13439 & 8228 & 2646 & 1474 & 8705 & 34492 \\
Cuzco & 22109 & 182904 & 417 & 47 & 37555 & 243032 \\
Huancavelica & 9682 & 80923 & 161 & 12 & 12291 & 103069 \\
Huánuco & 8182 & 47241 & 343 & 82 & 23143 & 78991 \\
Ica & 5529 & 33088 & 5380 & 5022 & 11236 & 60255 \\
Junín & 8728 & 129475 & 472 & 174 & 70910 & 209759 \\
La Libertad & 17071 & 57857 & 2467 & 8816 & 61125 & 147336 \\
Lambayeque & 8127 & 48599 & 2683 & 4087 & 23242 & 86738 \\
Lima & 50761 & 99764 & 15404 & 24290 & 35581 & 225800 \\
Loreto & 10479 & 29749 & 110 & 27 & 21540 & 61905 \\
Moquegua & 5956 & 19041 & 621 & 586 & 2581 & 28785 \\
Piura & 13930 & 79792 & 3854 & 74 & 37965 & 135615 \\
Puno & 8278 & 239161 & 224 & 37 & 11749 & 259449 \\
Tacna & 7469 & 21807 & 1299 & 222 & 5210 & 36007 \\
Tarapacá & 13418 & 16686 & 564 & 791 & 6766 & 38225 \\
Total & 371195 & 1554678 & 52588 & 51186 & 669457 & 2699104 \\
\hline
\end{tabular}

Fuente: Elaboración propia a partir del censo de 1876. 
Anexo 3. Población extranjera en el Perú según el censo de 1876

\begin{tabular}{|c|c|c|}
\hline \multicolumn{3}{|c|}{ Población extranjera en el Perú, 1876} \\
\hline Nacionalidad & $\mathrm{N}^{\circ}$ de personas & $\%$ \\
\hline Asiática & 49979 & 46,73 \\
\hline Chilena & 14235 & 13,31 \\
\hline Boliviana & 12321 & 11,52 \\
\hline Italiana & 6990 & 6,54 \\
\hline Ecuatoriana & 4086 & 3,82 \\
\hline Inglesa & 3386 & 3,17 \\
\hline Francesa & 2647 & 2,47 \\
\hline Española & 1699 & 1,59 \\
\hline Alemana & 1672 & 1,56 \\
\hline Norteamericana & 1132 & 1,06 \\
\hline Argentina & 602 & 0,56 \\
\hline Austriaca & 479 & 0,45 \\
\hline Portuguesa & 373 & 0,35 \\
\hline Brasileña & 316 & 0,30 \\
\hline Colombiana & 296 & 0,28 \\
\hline Granadina & 189 & 0,18 \\
\hline Cubana & 143 & 0,13 \\
\hline Mexicana & 138 & 0,13 \\
\hline Griega & 116 & 0,11 \\
\hline Escocesa & 111 & 0,10 \\
\hline Prusiana & 110 & 0,10 \\
\hline Suiza & 91 & 0,09 \\
\hline Sueca & 88 & 0,08 \\
\hline Belga & 75 & 0,07 \\
\hline Venezolana & 73 & 0,07 \\
\hline Noruega & 72 & 0,07 \\
\hline Danesa & 54 & 0,05 \\
\hline Holandesa & 34 & 0,03 \\
\hline Manileña & 34 & 0,03 \\
\hline Irlandesa & 30 & 0,03 \\
\hline Polinesia & 27 & 0,03 \\
\hline Rusa & 27 & 0,03 \\
\hline Polaca & 20 & 0,02 \\
\hline Jamaiquina & 16 & 0,01 \\
\hline Salvadoreña & 16 & 0,01 \\
\hline Japonesa & 15 & 0,01 \\
\hline Nicaragüense & 14 & 0,01 \\
\hline Paraguaya & 13 & 0,01 \\
\hline Uruguaya & 10 & 0,01 \\
\hline Otros & 49 & 0,05 \\
\hline Ignorada & 5184 & 4,85 \\
\hline Total & 106962 & 100,00 \\
\hline
\end{tabular}

Fuente: Elaboración propia sobre la base del censo de 1876. 


\section{Anexo 4. PEA estimada para 1876}

Población económicamente activa en el Perú según el censo de 1876

(Número de personas)

\begin{tabular}{|c|c|c|c|c|c|c|c|c|}
\hline \multicolumn{4}{|c|}{$\begin{array}{c}\text { Departamentos Profesionales Empleados } \\
\text { Técnicos/Artesanos }\end{array}$} & Obreros & \multicolumn{2}{|c|}{$\begin{array}{l}\text { Agricultores } \\
\text { No Calificados }\end{array}$} & \multirow{2}{*}{$\begin{array}{c}\text { Oficios } \\
\text { femeninos } \\
\text { de baja } \\
\text { remunera- } \\
\text { ción }\end{array}$} & \multirow{2}{*}{$\begin{array}{l}\text { Total } \\
19176\end{array}$} \\
\hline Amazonas & 43 & 149 & 736 & 25 & 9493 & 224 & & \\
\hline Ancash & 154 & 360 & 13026 & 12136 & 50970 & 9355 & 58581 & 144582 \\
\hline Apurímac & 20 & 149 & 3384 & 750 & 29013 & 4067 & 5588 & 42971 \\
\hline Arequipa & 612 & 1602 & 12687 & 14386 & 36888 & 12795 & 3519 & 82489 \\
\hline Ayacucho & 120 & 456 & 6446 & 371 & 54211 & 2859 & 18608 & 83071 \\
\hline Cajamarca & 194 & 558 & 7124 & 8318 & 39450 & 2198 & 36436 & 94278 \\
\hline Callao & 172 & 2567 & 6705 & 1058 & 363 & 1767 & 1155 & 13787 \\
\hline Cuzco & 245 & 1711 & 16091 & 9198 & 53347 & 11027 & 28198 & 119817 \\
\hline Huancavelica & 33 & 148 & 2638 & 1225 & 36883 & 1164 & 3816 & 45907 \\
\hline Huánuco & 47 & 239 & 1924 & 4989 & 22757 & 883 & 3325 & 34164 \\
\hline Ica & 166 & 442 & 2660 & 6049 & 16210 & 2470 & 827 & 28824 \\
\hline Junín & 176 & 459 & 4851 & 4972 & 55234 & 7580 & 28541 & 101813 \\
\hline La Libertad & 284 & 892 & 5825 & 12420 & 24184 & 2707 & 12842 & 59154 \\
\hline Lambayeque & 90 & 330 & 5770 & 6703 & 10873 & 3543 & 6489 & 33798 \\
\hline Lima & 1330 & 8823 & 15136 & 11243 & 46332 & 14076 & 6167 & 103107 \\
\hline Loreto & 32 & 157 & 4932 & 100 & 10605 & 2881 & 8421 & 27128 \\
\hline Moquegua & 67 & 203 & 1673 & 1459 & 12089 & 2102 & 1429 & 19022 \\
\hline Piura & 153 & 436 & 8695 & 4511 & 24540 & 5008 & 19551 & 62894 \\
\hline Puno & 135 & 457 & 14489 & 2553 & 81312 & 34590 & 19664 & 153200 \\
\hline Tacna & 115 & 597 & 2419 & 1869 & 7951 & 3086 & 2491 & 18528 \\
\hline Tarapacá & 109 & 1253 & 4206 & 10186 & 4295 & 2243 & 2347 & 24639 \\
\hline Total & 4297 & 21988 & 141417 & 114521 & 627000 & 126625 & 276501 & 1312349 \\
\hline
\end{tabular}

Fuente: Elaboración propia a partir del censo de 1876 


\section{Anexo 5. Salarios calculados por ocupación}

Salario anual por trabajador según categoría laboral de 1876 (En S/.)

\begin{tabular}{lccccccc}
\hline \multicolumn{1}{c}{$\begin{array}{c}\text { Departamento } \\
\text { Profesionales }\end{array}$} & Empleados & $\begin{array}{c}\text { Técnicos/ } \\
\text { Artesanos }\end{array}$ & Obreros & Agricultores & $\begin{array}{c}\text { No } \\
\text { Calificados }\end{array}$ & $\begin{array}{c}\text { Oficios feme- } \\
\text { ninos de baja } \\
\text { remunera- } \\
\text { ción }\end{array}$ \\
\hline Amazonas & 1297,0 & 450,0 & 260,0 & 130,0 & 84,4 & 48,0 & 36,0 \\
Ancash & 2202,4 & 636,0 & 246,9 & 176,4 & 55,5 & 73,2 & 54,9 \\
Apurímac & 2202,4 & 672,0 & 171,6 & 104,0 & 66,2 & 48,0 & 36,0 \\
Arequipa & 2753,0 & 936,0 & 230,5 & 141,1 & 100,0 & 61,8 & 46,4 \\
Ayacucho & 2202,4 & 672,0 & 171,6 & 104,0 & 58,3 & 48,0 & 36,0 \\
Cajamarca & 2331,8 & 840,0 & 420,0 & 104,0 & 64,7 & 48,0 & 36,0 \\
Callao & 2753,0 & 997,0 & 686,4 & 416,0 & 270,3 & 192,0 & 144,0 \\
Cusco & 2753,0 & 806,0 & 171,6 & 104,0 & 74,1 & 48,0 & 36,0 \\
Huancavelica & 1651,8 & 645,0 & 171,6 & 104,0 & 60,4 & 48,0 & 36,0 \\
Huánuco & 1585,7 & 654,7 & 327,1 & 155,9 & 143,0 & 67,1 & 50,4 \\
Ica & 2477,7 & 780,0 & 343,2 & 208,0 & 243,3 & 96,0 & 72,0 \\
Junín & 2753,0 & 772,0 & 252,4 & 184,3 & 156,0 & 68,1 & 51,1 \\
La Libertad & 2642,9 & 820,0 & 261,0 & 197,5 & 89,3 & 79,8 & 59,8 \\
Lambayeque & 2385,9 & 864,1 & 343,2 & 208,0 & 208,0 & 96,0 & 72,0 \\
Lima & 2753,0 & 997,0 & 616,0 & 377,2 & 270,3 & 177,6 & 133,2 \\
Loreto & 1297,0 & 469,7 & 171,6 & 104,0 & 55,0 & 48,0 & 36,0 \\
Moquegua & 1651,8 & 695,0 & 343,2 & 208,0 & 169,0 & 96,0 & 72,0 \\
Piura & 1651,8 & 720,0 & 301,8 & 144,6 & 122,7 & 70,9 & 53,2 \\
Puno & 2753,0 & 825,0 & 257,4 & 156,0 & 65,0 & 72,0 & 54,0 \\
Tacna & 1817,0 & 658,0 & 343,2 & 208,0 & 238,0 & 96,0 & 72,0 \\
Tarapacá & 1982,2 & 720,0 & 429,0 & 481,0 & 234,0 & 120,0 & 90,0 \\
\hline
\end{tabular}

Fuente: Elaboración propia en base al censo de 1876. 


\section{Anexo 6. Jornal por provincias en 1866}

Precio del jornal* en los pueblos de la República

\begin{tabular}{|c|c|c|}
\hline Poblaciones & Clases & Tipo del jornal (S/.) \\
\hline $\begin{array}{l}\text { Ciudad de Lima } \\
\text { Chorrillos } \\
\text { Callao } \\
\end{array}$ & 1era & 0,8 \\
\hline Provincia de Santa & $2 \mathrm{da}$ & 0,6 \\
\hline $\begin{array}{l}\text { Provincia de Cañete } \\
\text { Provincia de Chancay }\end{array}$ & 3era & 0,5 \\
\hline $\begin{array}{l}\text { Provincia de Trujillo } \\
\text { Provincia de Chiclayo Provincia de Pacasmayo } \\
\text { Provincia de Lambayeque } \\
\text { Ciudad del Cerro de Pasco } \\
\text { Provincia de Huarochirí } \\
\text { Departamento de Ica } \\
\text { Departamento de Moquegua } \\
\end{array}$ & $4 \mathrm{ta}$ & 0,4 \\
\hline $\begin{array}{l}\text { Provincia de Piura } \\
\text { Provincia de Payta } \\
\text { Provincia de Huaraz } \\
\text { Provincia de Huaylas } \\
\text { Provincia de Cajatambo } \\
\text { Provincia de Huánuco } \\
\text { Provincia de Tarma } \\
\text { Provincia de Yauyos } \\
\text { Provincia de Canta } \\
\text { Departamento de Puno } \\
\text { Provincia de Arequipa }\end{array}$ & $5 \mathrm{ta}$ & 0,3 \\
\hline
\end{tabular}

Departamento de Amazonas

Departamento de Loreto

Provincia de Ayabaca

Provincia de Huancavelica

Departamento de Cajamarca

Provincia de Pataz

Provincia de Huamachuco

Provincia de Otuzco

Provincia de Huari

Provincia de Pallasca

Provincia de Pomabamba

Provincia de Huamalíes

Provincia de Jauja

6ta

0,2

Provincia de Huancayo

Distritos de Huari, Paccho y Checras de Chancay

Departamento de Huancavelica

Departamento de Ayacucho

Departamento del Cusco

Provincia de Camaná

Provincia de Condesuyos

Provincia de la Unión

Provincia de Castilla

Provincia de Islay

Provincia de Yanqui

* Jornal diario calculado para 1866. Fuente: Rodríguez (1895) 
Anexo 7. Haciendas por departamento en 1876

Número de haciendas por departamento según el censo de 1876

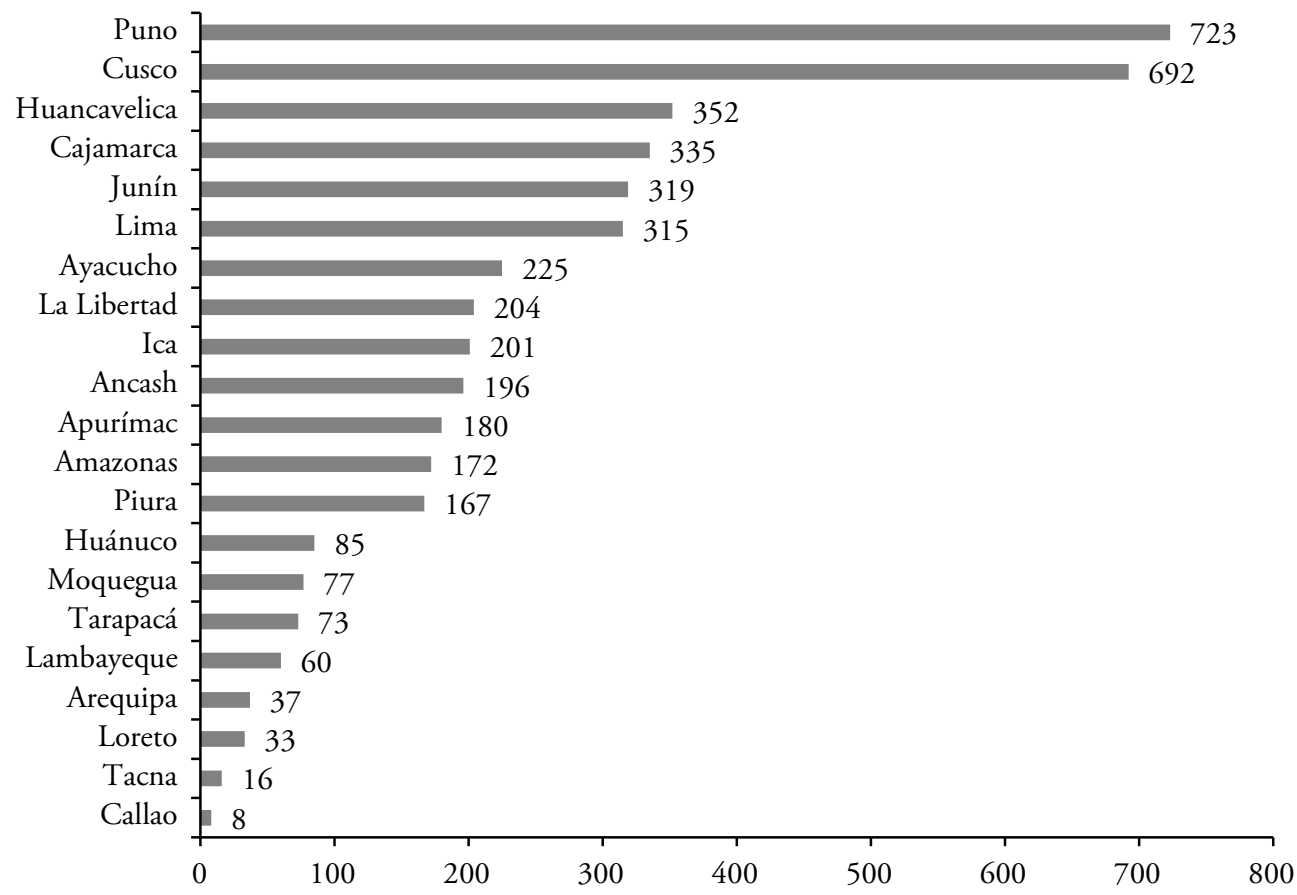

Fuente: Elaboración propia sobre la base del censo de 1876. 
Anexo 8. Patrones/Empresarios estimados para 1876

\begin{tabular}{lcc}
\hline \multicolumn{3}{c}{ Patrones/Empresarios para 1876} \\
\hline Departamento & $\begin{array}{c}\mathrm{N}^{\circ} \\
\text { de personas }\end{array}$ & $\begin{array}{c}\text { Salario anual } \\
\text { por trabajador } \\
(\mathrm{S} / .)\end{array}$ \\
\hline Amazonas & 172 & 2287,1 \\
Áncash & 403 & 3883,6 \\
Apurímac & 180 & 3883,6 \\
Arequipa & 104 & 4854,5 \\
Ayacucho & 239 & 3883,6 \\
Cajamarca & 387 & 4111,8 \\
Callao & 13 & 4854,5 \\
Cusco & 694 & 4854,5 \\
Huancavelica & 359 & 2912,7 \\
Huánuco & 121 & 2796,2 \\
Ica & 255 & 4369,1 \\
Junín & 986 & 4854,5 \\
La Libertad & 282 & 4660,3 \\
Lambayeque & 64 & 4207,2 \\
Lima & 407 & 4854,5 \\
Loreto & 34 & 2287,1 \\
Moquegua & 78 & 2912,7 \\
Piura & 206 & 2912,7 \\
Puno & 764 & 4854,5 \\
Tacna & 16 & 3204,0 \\
Tarapacá & 224 & 3495,2 \\
\hline Total & 5988 & 80933,9 \\
\hline F & & \\
\hline
\end{tabular}

Fuente: Elaboración propia sobre la base del censo de 1876.
Anexo 9. Población extranjera en Lima

\begin{tabular}{|c|c|c|}
\hline \multicolumn{3}{|c|}{ Población extranjera en Lima de 1876} \\
\hline Nacionalidad & $\mathrm{N}^{\circ}$ & $\%$ \\
\hline Asiática & 24288 & 68,38 \\
\hline Italiana & 3477 & 9,79 \\
\hline Francesa & 1521 & 4,28 \\
\hline Chilena & 1385 & 3,90 \\
\hline Ecuatoriana & 1348 & 3,80 \\
\hline Española & 783 & 2,20 \\
\hline Inglesa & 574 & 1,62 \\
\hline Alemana & 405 & 1,14 \\
\hline Norteamericana & 335 & 0,94 \\
\hline Boliviana & 215 & 0,61 \\
\hline Colombiana & 185 & 0,52 \\
\hline Argentina & 142 & 0,40 \\
\hline Austriaca & 124 & 0,35 \\
\hline Portuguesa & 96 & 0,27 \\
\hline Prusiana & 92 & 0,26 \\
\hline Cubana & 76 & 0,21 \\
\hline Venezolana & 54 & 0,15 \\
\hline Belga & 53 & 0,15 \\
\hline Mexicana & 49 & 0,14 \\
\hline Suiza & 41 & 0,12 \\
\hline Brasileña & 28 & 0,08 \\
\hline Escocesa & 28 & 0,08 \\
\hline Irlandesa & 24 & 0,07 \\
\hline Jamaiquina & 15 & 0,04 \\
\hline Japonesa & 15 & 0,04 \\
\hline Polaca & 14 & 0,04 \\
\hline Holandesa & 13 & 0,04 \\
\hline Manileña & 8 & 0,02 \\
\hline San Tomasinos & 8 & 0,02 \\
\hline Danesa & 7 & 0,02 \\
\hline Griega & 7 & 0,02 \\
\hline Rusa & 7 & 0,02 \\
\hline Salvadoreña & 7 & 0,02 \\
\hline Guineo & 5 & 0,01 \\
\hline Sueca & 5 & 0,01 \\
\hline Otros & 31 & 0,09 \\
\hline Ignorada & 53 & 0,15 \\
\hline Total & 35518 & 100,00 \\
\hline
\end{tabular}

Fuente: Elaboración propia sobre la base del censo de 1876. 


\section{REFERENCIAS}

Basadre, Jorge (2010). Perú independiente. Lima: El Comercio.

Bates, Robert, Coatsworht, John y Jeffrey Williamson (2007). Lost Decades: Postindependence Performance in Latin America and Africa. The Journal of Economic History, 67(4).

Berry, Albert (1989). Income distribution and foreign trade: the case of Peru. External trade and income distribution. París: OECD.

Berry, Albert (1990). International trade, government and income distribution in Peru since 1870. Latin American Research Review, 2, 31-59. Toronto: University of Toronto.

Berry, Albert (1998). Poverty, economic reform and income distribution in Latin America. Boulder: Lynne Rienner Publishers.

Bértola, Luis (2011). Institutions and the Historical Roots of Latin American Divergence. The Oxford Handbook of Latin American Economics. Oxford: Oxford University Press.

Bértola, Luis y José Antonio Ocampo (2010). Desarrollo, vaivenes y desigualdad. Una historia económica de América Latina desde la independencia. Madrid: Secretaría General Iberoamericana (SEGIB).

Bértola, Luis, Cecilia Castelnovo, Javier Rodríguez y Henry Willebald (2010). Between the colonial heritage and the first globalization boom: on income inequality in the southern cone. Journal of lberian and Latin American Economic History, 28(2).

Bonilla, Heraclio (1965). La crisis de 1872. Documentos de trabajo PUCP. No 64.

Carrillo, Ana Cecilia, Ciro Corilla, Diego Lévano, Roberto Rivas, Rosario Rivoldi y Susy Sánchez (2002). Etnicidad y discriminación racial en la historia del Perú. Lima: PUCP-Instituto Riva-Agüero, Banco Mundial.

Chocano, Magdalena (2010). Población, producción agraria y mercado interno, 1700-1824. Compendio de Historia Económica del Perú, Tomo 3. pp. 19-32.

Coatsworth, John (2008). Inequality, institutions and economic growth in Latin America. UK. Cambridge University Pres.

Contreras, Carlos (1996). Maestros, mistis y campesinos en el Perú rural del siglo XX. Lima: Instituto de Estudios Peruanos.

Contreras, Carlos (1999). El reemplazo del beneficio de patio en la minería peruana, 1850-1913. Revista de Indias, LIX(216).

Contreras, Carlos (2009). Política demográfica, crecimiento económico y formación del mercado laboral en el Perú del siglo veinte. Investigaciones de Historia Económica. No 13. 2009.

Contreras, Carlos (2010). El legado económico de la independencia del Perú. Lima. Lima. Pontificia Universidad Católica del Perú.

Contreras, Carlos (2012). La economía pública en el Perú después del guano y del salitre. Lima: Banco Central de Reserva del Perú - Instituto de Estudios Peruanos.

Contreras, Carlos, Stephan Gruber y Cristina Mazzeo (2012). Orígenes históricos de la desigualdad en el Perú. Lima: Pontificia Universidad Católica del Perú.

Cotler, Julio (1967). La mecánica de la dominación interna y del cambio social en el Perú. Lima: Instituto de Estudios Peruanos.

Dirección de Estadística del Perú (1879). Estadística de las minas de la República del Perú en 1878. Lima.

El Comercio, $1875-1877$

El Peruano, $1874-1876$

Elguera, Juan Ignacio (1876). Memoria especial presentada al Congreso Extraordinario de 1876 por el Ministro de Hacienda y Comercio. Lima. 
Elguera, Juan Ignacio (1876). Memoria presentada al Congreso Ordinario de 1876 por el Ministro de Hacienda y Comercio. Lima.

Elguera, Juan Ignacio (1876). Memoria presentada al Congreso Ordinario de 1876 por el Ministro de Hacienda y Comercio: anexo N. 4. Lima.

Escobal, Javier y Carmen Ponce (2010). Desigualdad en el Perú en las últimas tres décadas. En presentación de PowerPoint http://www.grade.org.pe/download/presentacion_javier_ escobal.pdf

Figueroa, Adolfo (2000). La exclusión social como una teoría de la distribución. Washington D.C.: The World Bank.

Figueroa, Adolfo (2003). La Sociedad Sigma: una teoría del desarrollo económico. Lima: Pontificia Universidad Católica del Perú.

Figueroa, Adolfo y Weisskoff, Richard (1974). Visión de las pirámides sociales: distribución del ingreso en América Latina. Serie de documentos de trabajo $\mathrm{N}^{\circ} 15$.

Garland, Alejandro (1905). Reseña industrial del Perú. Lima.

Gelman, Jorge (2010). Senderos que se bifurcan. Las economías de América Latina luego de las Independencias. En Institucionalidad y desarrollo económico de América Latina (pp. 19-41). Santiago de Chile: CEPAL.

Gootenberg, Paul (1995). Población y etnicidad en el Perú Republicano (siglo XIX). Lima: Instituto de Estudios Peruanos.

Hunt, Shane J. (1973). Growth and guano in nineteenth century Peru. Princeton: Princeton University.

Hunt, Shane J. (2011). La formación de la economía peruana. Distribución y crecimiento en la historia de América Latina. Lima: BCRP, PUCP, IEP.

Jiménez, Carlos (1922). Estadística industrial del Perú. Boletín del Cuerpo de Ingenieros de Minas del Perú, 105. Lima.

Kahhat, Farid (2014). El mundo versus Kuznets. http://www.americaeconomia.com/analisisopinion/el-mundo-versus-kuznets [Consulta: 24 de febrero de 2015]

Kuznets, Simon (1955). Economic growth and income inequality. The American Economic Review, 1.

Kuznets, Simon (2005). Kuznets's Inverted U-Curve Hypothesis: The Rise, Demise, and Continued Relevance of a Socioeconomic Law. Sociological Forum, 20(2), 209-244.

Lima, Concejo Departamental (1876). Presupuesto del Concejo Departamental para el bienio de julio de 1876 a junio 30 de 1878. Lima.

Maddinson Project (s.f.) http://www.ggdc.net/maddison/maddison-project/home.htm [Consulta: 15 de enero de 2014]

Martinet, Jean Baptiste (1977). La agricultura en el Perú. Lima: Centro Peruano de Historia Económica.

Mc Evoy, Carmen (2004). La huella republicana liberal en el Perú: Manuel Pardo: escritos fundamentales. Lima. Fondo editorial del Congreso del Perú.

Medina, Fernando (2001). Consideraciones sobre el indice de Gini para medir la concentración del ingreso. Santiago de Chile: CEPAL.

Mendoza, Waldo, Janneth Leyva y José Luis Flor (2011). La distribución del ingreso en el Perú 1980-2010. Lima: PUCP.

Milanovic, Branko (2005). Measuring international and global inequality. Princeton: Princeton University Press. 
Milanovic, Branko (2011). Los que tiene y los que no tienen. Una breve y singular historia de la desigualdad global. Madrid: Alianza Editorial.

Milanovic, Branko, Peter H. Lindert y Jeffrey G. Williamson (2010). Pre-industrial inequality. The Economic Journal, 551.

Ministerio de Gobierno (1876). Censo General de la República del Perú. Lima.

Ministerio De Gobierno (1878). Resumen del Censo General de Habitantes del Perú hecho en 1876. Lima.

Monsalve, Martín (2011). Industria y mercado interno, 1821-1930. Compendio de historia económica del Perú. Vol. 4. Lima.

Mücke, Ulrich (2010). Política y burguesía en el Perú. El Partido Civil antes de la Guerra con Chile. Lima: Instituto de Estudios Peruanos.

Noejovich, Héctor (2012). Desigualdad y desarrollo en América Latina: 1960-2010 ArgentinaChile-Colombia-Perú. Contabilidad y Negocios, 7(13), 71-93. Lima. PUCP.

Noejovich, Héctor y Alfredo Vento (2009). Guano, salitre y finanzas públicas: el Pacífico en el siglo XIX. Lima: PUCP.

Presupuesto general de gastos ordinarios o permanentes sancionados por el Congreso Extraordinario de 1875 para el bienio de 1875-1876. Lima1875.

Rodriguez, J.M. (1895). Estudios económicos y financieros y ojeada sobre la Hacienda Pública del Perú y la necesidad de su reforma. Lima: Banco del Herrador.

Salinas Sánchez, Alejandro (2013). Polos opuestos: salaries y costo de vida 1821-1879. Lima. Fondo Editorial UNMSM.

Sokoloff, Kenneth L. y Stanley L. Engerman (2000). History lessons institutions, factor endowments, and paths of development in the new world. Journal of Economic Perspectives, 3.

Tarapacá, Concejo Provincial (1877). Presupuesto general de ingresos y egresos del Honorable Concejo Provincial de la provincia litoral de Tarapacá: para el bienio que principiará el $1^{\circ}$ de julio de 1876 y terminará el 30 de junio de 1878 . Iquique.

Thorp, Rosemary, Maritza Paredes y Carlos Contreras (2011). El enraizamiento histórico de las desigualdades grupales: de la colonia a la Guerra con Chile. En La etnicidad y la persistencia de la desigualdad. El caso peruano. Lima: Instituto de Estudios Peruanos.

Twrdek, Linda y Kerstin Manzel (2013). La semilla de la abundancia y la miseria. Niveles de vida peruanos desde los inicios del periodo republicano hasta el fin de la era del guano. Economía, XXXVI(71), 151-180

Webb, Richard (2014). El Perú vs. Kuznets. http://elcomercio.pe/opinion/mirada-de-fondo/ peru-vs-kuznets-richard-webb-noticia-1727152 [Consulta: 24 de febrero de 2015]

Webb, Richard, Caballero, Adolfo Figueroa y Javier Iguíniz (1981). Distribución del ingreso en el Perú. Lima. Compilación del Taller de Economía, TECO.

Williamson, Jeffrey G. (1996). Globalization, convergence and history. The Journal of Economic History, 56, 2.

Williamson, Jeffrey G. (2002). Land, Labor and globalization in the third world, 1870-1940. The Journal of Economic History, 62, 1.

Yamada, Gustavo y Juan Francisco Castro (2012). Poverty, inequality, and social policies in Peru: As poor as it gets. Documento de discusión 7. Lima: Universidad del Pacífico.

Yepes del Castillo, E. (1970). El guano y su impacto en la economía y sociedad peruana (1840-1879). Lima: Centro de Investigaciones Socio-Económicas, Universidad Nacional Agraria La Molina. 